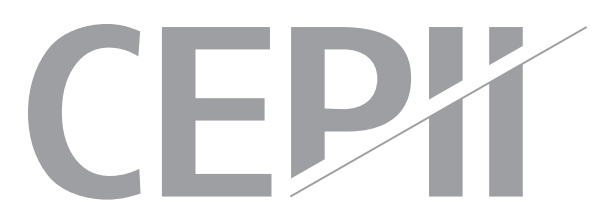

\title{
Uncertainty Shocks and Firm Creation: Search and Monitoring in the Credit Market
}

Thomas Brand, Marlène Isoré \& Fabien Tripier

Highlights

I A striking feature of the Great Recession in the US is the sharp drop in firm creation in 2008-2010 and its following slow recovery.

- We develop a model with two financial frictions, search and monitoring on the credit market, to study the role of uncertainty shocks in the firm creation process.

- Uncertainty shocks in the financial sector turn out to be a major business cycle contributor of both macrofinancial aggregates and firm dynamics.

- Uncertainty shocks explain most of the drop in firm creation and output during the Great Recession. 


\section{Abstract}

We develop a business cycle model where endogenous firm creation stems from two credit market frictions. First, entrepreneurs search for a lending relationship with a bank. Second, an optimal debt contract with monitoring is implemented. We analyze the interplay between both frictions, and embed it into an otherwise standard business cycle model, which we estimate with Bayesian techniques. We find that uncertainty shocks are a prime contributor to business cycle fluctuations in the US, not only for macro-financial aggregates but also for firm creation. Moreover, we point out that the credit search friction dampens the financial accelerator mechanism because default may imply the end of the lending relationship.

\section{Keywords}

Uncertainty, Financial Frictions, Search and Matching, Business Cycle, Firm Creation, Firm Dynamics.

\section{JEL}

D8, E3, E4, E5.

\section{Working Paper}

\section{CEPI}

CEPII (Centre d'Etudes Prospectives et d'Informations Internationales) is a French institute dedicated to producing independent, policyoriented economic research helpful to understand the international economic environment and challenges in the areas of trade policy, competitiveness, macroeconomics, international finance and growth.
CEPII Working Paper

Contributing to research in international economics

C C CEPII, PARIS, 2018

All rights reserved. Opinions expressed in this publication are those of the author(s) alone.

$\begin{array}{ll}\text { Editorial Director: } & \text { CEPII } \\ \text { Sébastien Jean } & \text { 20, avenue de Ségur } \\ & \text { TSA 10726 } \\ \text { Production: } & 75334 \text { Paris Cedex } 07 \\ \text { Laure Boivin } & +33153685500 \\ & \text { www.cepii.fr } \\ \text { No ISSN: } 1293-2574 & \text { Press contact: presse@ }\end{array}$




\title{
Uncertainty Shocks and Firm Creation: Search and Monitoring in the Credit Market ${ }^{1}$
}

\author{
Thomas Brand* , Marlène Isoré ${ }^{\dagger}$. and Fabien Tripier ${ }^{\ddagger}$.
}

\footnotetext{
${ }^{1}$ The views expressed in these papers are the authors' and do not represent those of the Bank of Finland or the Eurosystem. We thank two anonymous referees, Gene Ambrocio, Andrea Caggese, Miguel Casares, Fabrice Collard, Francesco Furlanetto, Simon Galle, Adam Gulan, Nobu Kiyotaki, François Langot, Zheng Liu, Thomas Lubik, Cyril Monnet, Erica Perego, Antti Ripatti, Aino Silvo, Jouko Vilmunen, Casper de Vries, Boromeus Wanengkirtyo, and Raf Wouters for fruitful comments, as well as participants to numerous seminars and conferences. Usual disclaimers apply. Marlène Isoré acknowledges the financial support of the OP Pohjola Research Group Foundation's grant 201600112. Fabien Tripier acknowledges the financial support of the Labex MME-DII's grant ANR-11-LBX-002301.

*CEPREMAP. Email: thomas.brand@cepremap.org

†University of Helsinki \& Bank of Finland. Email: marlene.isore@helsinki.fi

${ }^{\ddagger}$ EPEE, Univ Evry, Université Paris-Saclay \& CEPII. Email: fabien.tripier@univ-evry.fr
} 


\section{Introduction}

A striking feature of the Great Recession in the US is the sharp drop in firm creation in 20082010 and its following slow recovery (Figure 1). It is well known that the US economy has not recovered from the Great Recession as strongly as expected (e.g., Taylor (2014)), and the lack of firm creation has likely contributed to it (e.g Gourio et al. (2016), Clementi and Palazzo (2016)). Meanwhile, the contemporaneous rise in credit spread has been extensively calling for models with macro-financial linkages. Uncertainty shocks are particularly interesting in these models as they are often found to contribute to both macroeconomic and financial dynamics. This includes Christiano et al. (2014) (henceforth, CMR)'s so-called "risk shocks", defined as changes in the volatility of firms' idiosyncratic productivity. ${ }^{2}$ Yet, this literature mostly ignores the effects of uncertainty shocks on the extensive margins of activity, i.e firm creation, so far.

In this paper, we thus ask whether uncertainty shocks can explain the drop in firm creation observed in the data, along with the increase in credit spread, during the Great Recession. We develop a general equilibrium model where the credit market is characterized by an interplay between two frictions. First, a search friction between entrepreneurs and financial intermediaries (or "banks", for short). It allows us to endogenize an entry decision which depends on expected costs and gains of long-term lending relationships. Second, a match coincides with the implementation of a loan contract under a costly state-verification (henceforth, CSV) problem à la Townsend (1979). In short, banks do not observe the idiosyncractic productivity of entrepreneurs and therefore have to monitor them in case of default. Although this latter mechanism has become standard in macroeconomic models (e.g. Carlstrom and Fuerst (1997), Bernanke et al. (1999) - henceforth, BGG), it is usually restricted to existing firms in the econ-

\footnotetext{
2We adopt CMR's definition here and will therefore use the terms "uncertainty shocks" and "risk shocks" interchangeably throughout this paper, which affect firms' borrowing capacity via costly state-verification contracts, and thereby the real economy. As emphasized in Bloom (2014), the concept of "uncertainty" in this literature is a mixture of risk and Knightian uncertainty.
} 

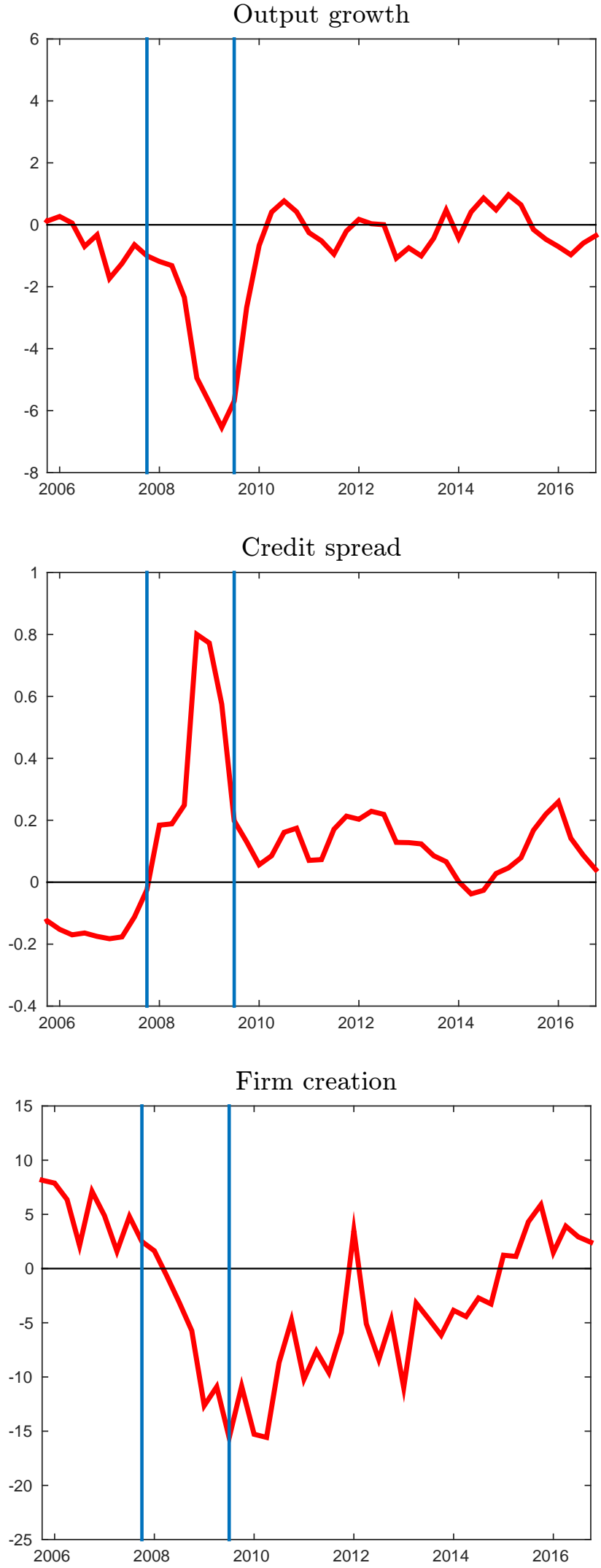

Figure 1 - Output Growth, Credit Spread, and Firm Creation in the US.

Note: All series are quarterly. Output growth is the quarterly year-to-year growth rate of real GDP per capita (percentage deviation from average). Credit spread is the difference between yields on BBA Corporate bonds and 10-year Government bonds (percentage points deviation from average). Firm creation is expressed per capita and in log (percentage deviation from average). Sources: FRED and BLS, see Appendix 1 for details. 
omy only, whereas we also consider its effects on firm creation here. By combining these two financial frictions, we analyze how search frictions affect the optimal terms of the CSV contract, but still nest the searchless economy as a limit case. We then embed these credit market features, namely search and monitoring, into an otherwise standard Dynamic Stochastic General Equilibrium (DSGE) model, which we estimate with Bayesian techniques for the US economy over the period 1980Q1-2016Q4.

The intuition on the effects of a risk shock is as follows. By definition, a risk shock increases the cross-sectional dispersion of entrepreneurs' productivity. In the CSV setup, this implies a higher loan default rate. As a consequence, the credit spread goes up to ensure the participation of bankers. Therefore, the demand for credit falls, leading to a macroeconomic downturn, characterized by drops in investment and output. In terms of firm dynamics, the entrepreneurial activity becomes less profitable, both because of the macroeconomic contraction and because bankers' share increases. For new potential entrepreneurs, searching for a lending relationship is thus less attractive, such that firm creation slows down. Simultaneously, defaults on loans become more frequent and are associated with an increase in firm destruction. The combination of lower firm creation and higher firm destruction overall contributes to a persistent decline in the number of productive firms in the economy. Overall, uncertainty shocks thus generate appealing responses of both macro-financial aggregates and firm dynamics.

From a quantitative point of view, our main results are as follows. First, uncertainty shocks turn out to be a major business cycle contributor of both macro-financial aggregates and firm dynamics. Indeed, the variance decomposition reveals that they are the first contributor to business cycles fluctuations, not only for credit spread and credit growth, in line with the literature, but also for firm creation. Second, during Great Recession episode in particular, uncertainty shocks explain most of the initial drop in firm creation and output, together with the rise in credit 
spread. However, they rapidly vanish in the aftermath of the crisis, while firm creation remains low due to other reasons, such as productivity and investment efficiency shocks in particular. Third, as for the importance of the credit search friction, we find that an average entrepreneur in our sample pays two third of a quarterly income over the search for its lending relationship. Finally, we show that the credit search friction tends to dampen the financial acceleration effect of uncertainty shocks on macro-financial variables as compared to a model with CSV only. Indeed, entrepreneurs chose to default less when default is associated with a risk of losing their lending relationship and having to search for a new one.

The paper continues as follows. The rest of the Introduction reviews the related literature. Section 2 presents the core of our model, which consists of the optimal loan contracting problem between entrepreneurs and banks in the presence of search frictions. The rest of the general equilibrium environment is standard and relegated to Appendix. Section 3 provides a Bayesian estimation of the model and simulations of an uncertainty shock in particular. Section 4 presents counterfactual exercises in order to explicit the mechanism at play in the model, as well as external sectoral-level data evidence on the role of uncertainty shocks on firm dynamics. Finally, Section 5 concludes.

\section{Literature review}

Our work relates to several strands of literature. First, we contribute to the literature on macroeconomic effects of uncertainty shocks. In Bloom (2009)'s seminal paper, uncertainty shocks take the form of an increase in the variance of firms' productivity, at individual, sectoral, and aggregate levels. ${ }^{3}$ The existence of non-monotonous capital and labor adjustment costs makes firms occasionally enter zones of inactivity as uncertainty shocks hit. As a consequence,

\footnotetext{
${ }^{3}$ Alternatively, Fernández-Villaverde et al. (2015) consider uncertainty on fiscal policy and Basu and Bundick (2017) uncertainty in agents' preferences.
} 
investment and hiring break down such that the economy enters a recession. CMR's definition of risk shocks is close (variance of firms' idiosyncratic productivity) but the transmission channel very different as it relates to the optimal debt contract. We here build on the latest to incorporate credit search frictions, and thereby firm dynamics. Other recent papers also assess the effects of uncertainty shocks through search and matching frictions, such as Leduc and Liu (2016) and Schaal (2017), yet on the labor market and not the credit market as we do here. Moreover, the mechanism through which the search friction operates differ. Indeed, in Leduc and Liu (2016), uncertainty shocks create an option value of waiting rather than posting new vacancies for firms. In our paper, uncertainty shocks also make firms better off while waiting rather than searching for a bank, but this is due to their deteriorated financial prospects on the credit market rather than to the option value of irreversible costs.

Second, our paper contributes to the literature on credit market search and matching frictions. Specifically, new entrepreneurs have to search for banks from whom they could obtain a loan in order to start their business, similarly to Mortensen and Pissarides (1994)'s job search of unemployed workers. The seminal works in this area, Den Haan et al. (2003) and Wasmer and Weil (2004), have further been extended to address puzzles in labor market dynamics by PetroskyNadeau and Wasmer (2013, 2015). Empirically, Dell'Ariccia and Garibaldi (2005), Herrera et al. (2011), Craig and Haubrich (2013), and Hyun and Minetti (2014) have documented the importance of credit search in the allocation of bank credit to firms. A common feature in this literature is the Nash bargaining rule, which splits the surplus of a lending relationship between the entrepreneur and the bank, exactly as it does split the match surplus on the labor market in Mortensen and Pissarides (1994). In particular, Wasmer and Weil (2004), Petrosky-Nadeau and Wasmer (2013), Petrosky-Nadeau and Wasmer (2015), and Beaubrun-Diant and Tripier (2015) all use Nash bargaining on credit markets. ${ }^{4}$ Here, the novelty is that we adopt the optimal debt

\footnotetext{
${ }^{4}$ Alternative contracts have been related to specific moral hazard (Den Haan et al. (2003)) or adverse selection
} 
contract with costly state-verification, which is more commonly used in the banking and macrofinance literatures (Townsend (1979), Carlstrom and Fuerst (1997), BGG). That allows us to study the impact of search on the terms of the optimal debt contract, namely the amount of loan, the interest rate on the loan, and the productivity level that entails default on the loan. In particular, we find that whenever loan default is associated with a potential separation of the lending relationship, the incentive to default is reduced for entrepreneurs, mitigating the effects of adverse shocks on aggregate variables. It is worth mentioning that Arseneau et al. (2017) recently built a model with a CSV contract and search frictions, but the contract is at play on the primary credit market while search frictions are on the OTC market. As far as we know, we are the first to combine a search friction and a CSV problem directly on the same credit market.

Third, our paper relates to the literature on firm dynamics in business cycles. Since the seminal works by Jaimovich and Floetotto (2008) and Bilbiie et al. (2012), many papers have analyzed causes and consequences of fluctuations in the number of incumbent firms in an economy (e.g Bergin and Corsetti (2008); Lewis (2009); Lewis and Poilly (2012); Lewis and Stevens (2015); Lewis and Winkler (2017); Gourio et al. (2016); Clementi and Palazzo (2016)). Some of them directly relate firm entry to financial frictions, starting from Cooley and Quadrini (2001) to Poutineau and Vermandel (2015) or Rossi (2016). Our search and matching approach provides an alternative way to formalize firm dynamics, with several advantages. First, while firm entry takes place in monopolistically competitive markets in the abovementioned literature, it does so in perfectly competitive markets in our setup. This is useful to analyze the role of financial frictions net of any other markup effects. Second, although debt contracts are set-up for one period, the presence of costly search here gives a value to the long-term relationship between entrepreneurs and banks. Growing evidence demonstrates the importance of lending relationships for the macroeconomic effect of financial crises, in particular in the US (e.g. Chodorow-Reich (Chamley and Rochon (2011)) problems. 
(2014); Darmouni (2016)), and in Europe (e.g. Sette and Gobbi (2015)). ${ }^{5}$ Third, it rationalizes a congestion externality in firm creation, which has been found important in the above literature. Finally, it is worth mentioning that Becsi et al. (2013) also investigated the role of credit search frictions on firm dynamics. However, they do so with a steady-state analysis only, i.e without the business cycle effects and estimations that we deliver here.

\section{Model}

The economy is populated by entrepreneurs, infinitely-lived households - who own monopolistic intermediate producers, a competitive final good sector, and financial intermediaries -, and a public authority. We only explicit the credit market in this Section, while the rest of the model is DSGE-standard and relegated to Appendix.

\subsection{Entrepreneurs}

\subsubsection{Population and transitions across states}

Entrepreneurs' population is separate from households. In each period of time, an exogenous fraction $\left(1-\gamma_{t}\right)$ dies and is born. ${ }^{6}$ More importantly, during their lifetime, entrepreneurs evolve across three distinct states, respectively 'passive', 'unmatched', and 'matched'. These transitions go as follows:

- When new-born, an entrepreneur is always 'passive'.

- He/she becomes 'unmatched' when starting to search for a 'lending relationship'.

- When a relationship is established, the entrepreneur is referred to as 'matched' with the bank. A one-period debt can then be (optimally) contracted, and further renewed in each and every

\footnotetext{
${ }^{5}$ Rocheteau et al. (2017) recently incorporated credit market search frictions in a New Monetarist model to study optimal monetary policy with endogenous formation of lending relationships.

${ }^{6}$ This fraction is time-varying to allow for a shock in the Bayesian estimation.
} 
period as long the lending relationship continues.

- Some entrepreneurs may default on their loan (since their business is risky), among which a fraction separates from their bank. In that case, they become 'unmatched' again, or passive again if searching for a new bank is not profitable enough.

Figure 2 summarizes the timeline of 'unmatched' and 'matched' entrepreneurs.

\subsubsection{Search for a loan}

A constant returns-to-scale technology matches new lending relationships as

$$
\text { new lending relationships } t_{t}=z^{c}\left(u_{t}^{e}\right)^{\alpha^{c}}\left(u_{t}^{b}\right)^{1-\alpha^{c}}
$$

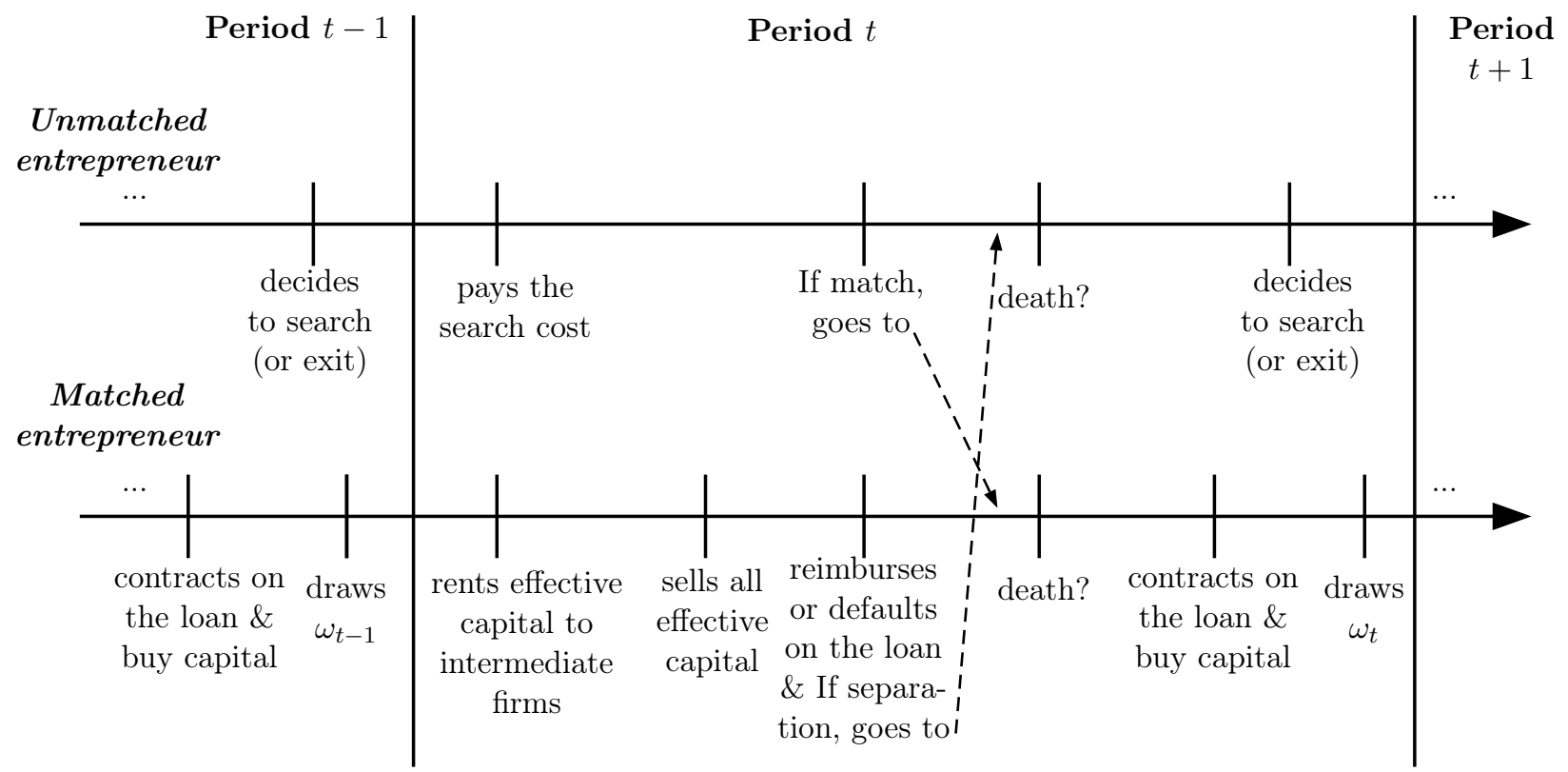

Figure 2 - Timeline, for matched and unmatched entrepreneurs 
where $u_{t}^{e}$ denotes the mass of unmatched entrepreneurs at time $t, u_{t}^{b}$ the mass of bankers searching for an entrepreneur at time $t, z^{c}$ the efficiency of the matching process, and $0<$ $\alpha^{c}<1$ a parameter. The matching probability is thus given by

$$
p_{t}^{\theta} \equiv \frac{\text { creditflows }}{u_{t}^{e}}=z^{c} \theta_{t}^{\alpha^{c}-1}
$$

where

$$
\theta_{t} \equiv \frac{u_{t}^{e}}{u_{t}^{b}}
$$

is referred to as the credit market tightness.

An unmatched entrepreneur's asset value can be written as

$$
\mathcal{E}_{t-1}^{u}=-D_{t}^{S}+\gamma_{t} \beta^{e}\left[p_{t}^{\theta} \mathcal{E}_{t}^{m}+\left(1-p_{t}^{\theta}\right) \mathcal{E}_{t}^{u}\right]
$$

where $D_{t}^{S}$ is a periodic cost of search, $\beta^{e}$ denotes entrepreneurs' discount factor, and where $\mathcal{E}_{t}^{m}$ is the expected present-value of being matched at the end of period $t{ }^{7}$ As for the timing of events, we assume that the decision to search is taken at the end of period $t-1$ (hence, the value of being unmatched $\mathcal{E}_{t-1}^{u}$ ), knowing all time $t$ variables. Hence, there is no expectation operator in (4). However, the value of being matched, $\mathcal{E}_{t}^{m}$ will incorporate expectations on both idiosyncratic and aggregate shocks.

\subsubsection{Production and long-term value of a lending relationship}

At the end of period $t$, all matched entrepreneurs chose their individual capital holding $K_{t+1}$ for the next period, bought at market price $Q_{k, t}$, taken as given, from households. This capital purchase is made using their personal wealth, $N_{t+1}$, and a one-period debt amount $B_{t+1}$ con-

\footnotetext{
${ }^{7}$ The search cost is time-indexed here but a fixed parameter in real detrended terms (see F).
} 
tracted optimally with the bank at the end of time $t$ (see further below). Thus, it satisfies the constraint

$$
Q_{K, t} K_{t+1}=N_{t+1}+B_{t+1}
$$

Note that both types of funding are always required. In other words, entrepreneurs can never become so rich that they would not need intermediation and never too poor that they would not be able to borrow. ${ }^{8}$

This $K_{t+1}$ "raw" capital is then transformed into $\omega K_{t+1}$ "efficiency" units, where $\omega$ is an idiosyncratic productivity shock with unit-mean log-normal distribution. The standard deviation of $\log \omega$, denoted $\sigma_{\omega, t}$, is an "uncertainty" shock, itself following an exogenous stochastic process as

$$
\log \sigma_{\omega, t}=\left(1-\rho_{\sigma}\right) \log \sigma_{\omega}+\rho_{\sigma} \log \sigma_{\omega, t-1}+\varepsilon_{\omega, t}
$$

with

$$
\varepsilon_{\omega, t}=\xi_{0, t}+\xi_{1, t-1}+\ldots+\xi_{p, t-p}
$$

where $\xi_{0, t}$ and $\xi_{j, t-j, j}>0$ are respectively unanticipated and anticipated (or "news") components.

Each unit of efficient capital yields a (gross) return $R_{t+1}^{k}$. As an entrepreneur, this is taken as given. However, in general equilibrium, it is endogenously determined with, among other things, the demand for capital by monopolistic intermediate good producers. ${ }^{9}$ The total return on efficient capital is therefore given by $R_{t+1}^{k} \bar{\omega}_{t+1} Q_{K, t} K_{t+1}$. According to a CSV loan contract, the entrepreneur can either (i) repay the loan $B_{t+1}$ with state-contingent (gross) interest rate $Z_{t+1}$, or (ii) default on the loan, in which case the bank seizes all entrepreneur's revenue net

\footnotetext{
${ }^{8}$ Technically, the latter case is avoided by a negligible amount of wealth transferred from households to entrepreneurs.

${ }^{9}$ The general equilibrium expression for this return is relegated to Appendix, equation (3.30).
} 
of a fraction $\mu$ spent on monitoring costs. Thus, there is a threshold value $\bar{\omega}$ such that an entrepreneur pays back the loan if $\omega>\bar{\omega}_{t+1}$, and default otherwise, i.e such that

$$
R_{t+1}^{k} \bar{\omega}_{t+1} Q_{K, t} K_{t+1}=B_{t+1} Z_{t+1}
$$

The value of this default threshold is a control variable in the financial contract as an entrepreneur optimally decides whether to default or not in equilibrium (see Section 2.3.2). Note that, despite the long-term nature of the lending relationship, the loan $B_{t+1}$ is contracted for one period only, and renegotiated in each of the following periods. However, we assume that, in case of default, a lending relationship may be exogenously severed, with probability $s^{c}$, which gives an additional long-term penalty as compared to BGG specification.

Therefore, at the end of period $t$, the asset value of a matched entrepreneur is

$$
\begin{gathered}
\mathcal{E}_{t}^{m}=\mathrm{E}_{t}\left\{\int_{\bar{\omega}_{t+1}}^{\infty}\left[R_{t+1}^{k} \omega_{t}\left(N_{t+1}+B_{t+1}\right)-B_{t+1} Z_{t+1}\right] d F_{t}+\left(1-\gamma_{t+1}\right) P_{t+1} C_{t+1}^{e}\right\} \\
+\beta^{e} \mathrm{E}_{t}\left\{\gamma_{t+1}\left[\int_{\bar{\omega}_{t+1}}^{\infty} \mathcal{E}_{t+1}^{m} d F_{t}+s^{c} \int_{0}^{\bar{\omega}_{t+1}} \mathcal{E}_{t+1}^{u} d F_{t}+\left(1-s^{c}\right) \int_{0}^{\bar{\omega}_{t+1}} \mathcal{E}_{t+1}^{m} d F_{t}\right]\right\}
\end{gathered}
$$

The first bracket in (9) consists of the entrepreneur's profit net of loan reimbursement. ${ }^{10}$ Second, $C_{t+1}^{e}$ is the consumption level of the matched entrepreneur who dies within the current period, with probability $\left(1-\gamma_{t+1}\right)$. This is the only source of consumption for an entrepreneur, taken as exogenous at the individual level, but determined by aggregate net entrepreneurial profits in each period (see Section 2.4). The remaining terms in (9) are the entrepreneur's continuation value, determined by the level of the idiosyncratic draw. Indeed, a good draw implies to remain matched in the following period, while a bad draw may lead to separation with probability $s^{c}$.

\footnotetext{
${ }^{10}$ This value is positive for an idiosyncratic productivity draw above the threshold, and zero otherwise as the banker then seizes the entire value of production.
} 
Denoting $F_{t}(\omega) \equiv F\left(\omega_{t+1}, \sigma_{\omega, t}\right)$ the cumulative distribution function of $\omega$ and $\Gamma_{t}\left(\bar{\omega}_{t+1}\right)$ the bank's share of entrepreneurial earnings, defined as

$$
\Gamma_{t}\left(\bar{\omega}_{t+1}\right) \equiv\left[1-F_{t}\left(\bar{\omega}_{t+1}\right)\right] \bar{\omega}_{t+1}+G_{t}\left(\bar{\omega}_{t+1}\right), \text { with } G_{t}\left(\bar{\omega}_{t+1}\right) \equiv \int_{0}^{\bar{\omega}_{t+1}} \omega d F_{t}(\omega)
$$

we can simplify (9) as

$$
\begin{aligned}
& \mathcal{E}_{t}^{m}=\mathrm{E}_{t}\left\{\left[1-\Gamma_{t}\left(\bar{\omega}_{t+1}\right)\right] R_{t+1}^{k}\left(N_{t+1}+B_{t+1}\right)+\left(1-\gamma_{t+1}\right) P_{t+1} C_{t+1}^{e}\right\} \\
&+\beta^{e} \mathrm{E}_{t}\left\{\gamma_{t+1}\left[\mathcal{E}_{t+1}^{m}-F_{t}\left(\bar{\omega}_{t+1}, \sigma_{t}\right) s^{c}\left(\mathcal{E}_{t+1}^{m}-\mathcal{E}_{t+1}^{u}\right)\right]\right\}
\end{aligned}
$$

In absence of separation $\left(s^{c}=0\right)$, this profit function would be identical to a search-frictionless economy, that we thus nest as a particular case of our model. However, whenever $s^{c}>0$, the additional term stands for the loss of surplus from severing a lending relationship.

\subsection{Banks}

Bankers' population is constant over time. As of time $t$, a fraction $u_{t}^{b}$ is "unmatched", at no cost, while the rest is engaged in a lending relationship with an entrepreneur. ${ }^{11}$

At the end of period $t-1$, a banker's value of being unmatched is

$$
\mathcal{F}_{t-1}^{u}=E_{t} \beta_{t, t+1}^{\star}\left[\theta_{t} p_{t}^{\theta} \mathcal{F}_{t}^{m}+\left(1-\theta_{t} p_{t}^{\theta}\right) \mathcal{F}_{t}^{u}\right]=E_{t} \beta_{t, t+1}^{\star}\left[\theta_{t} p_{t}^{\theta}\left(\mathcal{F}_{t}^{m}-\mathcal{F}_{t}^{u}\right)+\mathcal{F}_{t}^{u}\right]
$$

where $\theta_{t} p_{t}^{\theta}$ is the probability to match with an entrepreneur in period $t, \mathcal{F}_{t}^{m}$ is the value of being matched as of time $t$, and $\beta_{t, t+1}^{\star}$ is the stochastic discount factor. ${ }^{12}$

\footnotetext{
${ }^{11}$ We assume one-to-one matching without loss of generality here. Hence, there are as many matched bankers as matched entrepreneurs at the aggregate level, $m_{t}$, as of time $t$.

${ }^{12}$ Unlike entrepreneurs, we assume that the banks are owned by households. Their full problem is derived in Appendix, and their stochastic discount factor given by equation (3.19) in particular.
} 
Upon a match, the banker provides the entrepreneur with the one-period loan $B_{t+1}$ at interest rate $Z_{t+1}$. The banker also pays for monitoring costs $\mu$ in case of default. This corresponds to a periodic share of entrepreneurial incomes net of monitoring costs equal to $\Gamma_{t}\left(\bar{\omega}_{t+1}\right)-\mu G_{t}\left(\bar{\omega}_{t+1}\right)$ with $\Gamma_{t}\left(\bar{\omega}_{t+1}\right)$ and $G_{t}\left(\bar{\omega}_{t+1}\right)$ defined in (10). The contract terms are further renegotiated in each and every period as long as the lending relationship continues. The termination of the relationship arrives either with the entrepreneur's death, with probability $\left(1-\gamma_{t+1}\right)$, or with separation conditional on default, with probability $\gamma_{t+1} F_{t}\left(\bar{\omega}_{t+1}\right) s^{c}$. A banker's value of being matched to an entrepreneur is thus given by

$$
\begin{aligned}
\mathcal{F}_{t}^{m} & =E_{t}\left\{R_{t+1}^{k} Q_{K, t} K_{t+1}\left[\Gamma_{t}\left(\bar{\omega}_{t+1}\right)-\mu G_{t}\left(\bar{\omega}_{t+1}\right)\right]-R_{t} B_{t+1}\right. \\
& \left.+\beta_{t, t+1}^{\star}\left[\gamma_{t+1} \mathcal{F}_{t+1}^{m}+\left(1-\gamma_{t+1}\right) \mathcal{F}_{t+1}^{u}-\gamma_{t+1} F_{t}\left(\bar{\omega}_{t+1}\right) s^{c}\left(\mathcal{F}_{t+1}^{m}-\mathcal{F}_{t+1}^{u}\right)\right]\right\}
\end{aligned}
$$

where $R_{t}$ is the short-term risk-free rate at which the bank obtains the loan amount $B_{t+1}$ from households. It is worth noting that the presence of monitoring costs implies a positive interest rate spread in spite of a perfectly competitive market here.

\subsection{Equilibrium}

\subsubsection{Entrepreneurs' free entry}

Entrepreneurs who are not matched can decide either to search or to be passive, in which case they bear no cost and receive no revenue. Therefore, they prefer to search when the value of searching is at least as high as the value of being passive, i.e $\mathcal{E}_{t}^{u} \geq 0, \forall t$. We assume that the population of entrepreneurs is large enough such that this condition holds with equality in equilibrium. 
This implies that equation (4) can be rewritten as

$$
\frac{D_{t}^{S}}{p_{t}^{\theta}}=\gamma_{t} \beta^{e} \mathcal{E}_{t}^{m}
$$

and equation (11), using equation (5), becomes

$$
\begin{array}{r}
\mathcal{E}_{t}^{m}=\mathrm{E}_{t}\left\{\left[1-\Gamma_{t}\left(\bar{\omega}_{t+1}\right)\right] R_{t+1}^{k} Q_{K, t} K_{t+1}+\left(1-\gamma_{t+1}\right) P_{t+1} C_{t+1}^{e}\right. \\
\left.+\left[1-F_{t}\left(\bar{\omega}_{t+1}\right) s^{c}\right] \frac{D_{t+1}^{S}}{p_{t+1}^{\theta}}\right\}
\end{array}
$$

which, together with (14), gives the equilibrium condition

$$
\begin{array}{r}
\frac{D_{t}^{S}}{p_{t}^{\theta}}=\gamma_{t} \beta^{e} \mathrm{E}_{t}\left\{\left[1-\Gamma_{t}\left(\bar{\omega}_{t+1}\right)\right] R_{t+1}^{k} Q_{K, t} K_{t+1}\right. \\
+\left(1-\gamma_{t+1}\right) P_{t+1} C_{t+1}^{e} \\
\left.+\left[1-F_{t}\left(\bar{\omega}_{t+1}\right) s^{c}\right] \frac{D_{t+1}^{S}}{p_{t+1}^{\theta}}\right\}
\end{array}
$$

Hence, the expected cost of search (LHS) must be equal to the expected gain from search (RHS), given again by the share of production revenues received by an entrepreneur, the nonsurvival payoff, and the continuation value of the lending relationship.

\subsubsection{The optimal financial contract}

Let us now derive the optimality conditions of the financial contract. The terms of the contract are the level of the loan, $B_{t+1}$, the gross interest rate on the loan, $Z_{t+1}$, and the default threshold, $\bar{\omega}_{t+1}$. They are determined in a problem which consists in maximizing the expected present-value of a (matched) entrepreneur subject to participation of the banker.

In our economy with search frictions, a banker accepts to participate in the credit market if and only if the value of being matched is at least as high as the value of being unmatched, i.e until 
$\mathcal{F}_{t}^{m}-\mathcal{F}_{t}^{u}=0$. Substituting (12) and (14), this can be rewritten as

$$
R_{t} B_{t+1}=R_{t+1}^{k} Q_{K, t} K_{t+1}\left[\Gamma_{t}\left(\bar{\omega}_{t+1}\right)-\mu G_{t}\left(\bar{\omega}_{t+1}\right)\right]
$$

where all the $t+1$ terms here are known at the end of period $t$. This expression turns out to be identical to the search-frictionless BGG-CMR economy. It expresses that a banker's cost of borrowing (LHS) must be equal, in equilibrium, to his/her expected share of the entrepreneurial incomes net of monitoring costs (RHS).

Therefore, an entrepreneur maximizes (15) subject to (17). The first-order condition with respect to $B_{t+1}$ is

$$
\mathrm{E}_{t}\left\{\left[1-\Gamma_{t}\left(\bar{\omega}_{t+1}\right)\right] \frac{R_{t+1}^{k}}{R_{t}}\right\}=\mathrm{E}_{t}\left\{\lambda_{t+1}^{c}\left\{1-\frac{R_{t+1}^{k}}{R_{t}}\left[\Gamma_{t}\left(\bar{\omega}_{t+1}\right)-\mu G_{t}\left(\bar{\omega}_{t+1}\right)\right]\right\}\right\}
$$

and the first-order condition with respect to $\bar{\omega}_{t+1}$ is

$$
E_{t}\{R_{t+1}^{k} Q_{K, t} K_{t+1}\left[\lambda_{t+1}^{c}\left[\Gamma_{t}^{\prime}\left(\bar{\omega}_{t+1}\right)-\mu G_{t}^{\prime}\left(\bar{\omega}_{t+1}\right)\right]-\Gamma_{t}^{\prime}\left(\bar{\omega}_{t+1}\right)\right]-\underbrace{F_{t}^{\prime}\left(\bar{\omega}_{t+1}\right) s^{c} \frac{D_{t+1}^{S}}{p_{t+1}^{\theta}}}_{\text {search frictions }}\}=0
$$

with $\left.\Gamma_{t}^{\prime} \equiv \frac{\partial \Gamma\left(\omega_{t+1}, \sigma_{\omega, t}\right)}{\partial \omega}\right|_{\omega=\bar{\omega}_{t+1}},\left.G_{t}^{\prime} \equiv \frac{\partial G\left(\omega_{t+1}, \sigma_{\omega, t}\right)}{\partial \omega}\right|_{\omega=\bar{\omega}_{t+1}}$, and $\left.F_{t}^{\prime} \equiv \frac{\partial F\left(\omega_{t+1}, \sigma_{\omega, t}\right)}{\partial \omega}\right|_{\omega=\bar{\omega}_{t+1}}$ and where $\lambda_{t+1}^{c}$ denotes the Lagrange multiplier associated with the participation constraint. The third term of the optimal contract is the loan interest rate, $Z_{t+1}$, determined by (8). The presence of credit search directly affects the contract through the last term in equation (19), but leaves (17) and (18) unchanged as compared to a search frictionless but otherwise identical economy. This additional term shows that there exists a positive value associated with long-term lending relationships which comes from the fact that searching again (for a new relationship) would 
be costly. Therefore, the optimal default threshold $\bar{\omega}_{t+1}$ is lower when $s^{c}>0$ (search) versus $s^{c}=0$ (no search).

Finally, using (5) and (17), an individual entrepreneur's leverage can be written as

$$
L_{t} \equiv \frac{Q_{K, t} K_{t+1}}{N_{t+1}}=\frac{1}{1-\frac{R_{t+1}^{k}}{R_{t}}\left[\Gamma_{t}\left(\bar{\omega}_{t+1}\right)-\mu G_{t}\left(\bar{\omega}_{t+1}\right)\right]}
$$

\subsection{Aggregation}

Entrepreneurs across different states (passive, searching, and producing) and their relative masses affect aggregation. In particular, market-clearing for the physical capital requires $\bar{K}_{t}=$ $m_{t} K_{t}$ where $\bar{K}_{t}$ is the aggregate capital supply from households and $m_{t}$ the number of matched entrepreneurs at time $t$. Similarly for credit, $\bar{B}_{t}=m_{t} B_{t}$ and for the aggregation of net worth, $\bar{N}_{t}=m_{t} N_{t} \cdot{ }^{13}$

Accordingly, the aggregate leverage is identical to the individual leverage (20) since

$$
\bar{L}_{t} \equiv \frac{Q_{K, t} \bar{K}_{t+1}}{\bar{N}_{t+1}}=\frac{Q_{K, t} K_{t+1} m_{t+1}}{N_{t+1} m_{t+1}}=\frac{Q_{K, t} K_{t+1}}{N_{t+1}}=L_{t}
$$

Then, aggregate net worth is given by

$$
\bar{N}_{t+1}=\frac{m_{t+1}}{m_{t}}\left\{\gamma_{t}\left[1-\Gamma_{t-1}\left(\bar{\omega}_{t}\right)\right] R_{t}^{k} Q_{K, t-1} \bar{K}_{t}+\bar{W}_{t}^{e}\right\}
$$

where the first term in curly brackets are matched entrepreneurs' incomes at the end of period $t-1$, provided that they survive with probability $\gamma_{t}$. The second term $\bar{W}_{t}^{e} \equiv m_{t} W_{t}^{e}$ is an aggregate transfer from households to matched entrepreneurs at the end of period $t$, set to a

\footnotetext{
${ }^{13}$ The aggregate net worth $\bar{N}_{t}$ is split among matched entrepreneurs at the end of each period $t$.
} 
negligible value in the calibration. Finally, the ratio $\frac{m_{t+1}}{m_{t}}$ accounts for the growth of matched entrepreneurs between $t$ and $t+1$.

The aggregate resource constraint, expressed in real terms, is

$$
Y_{t}=C_{t}+G_{t}+\frac{I_{t}}{\Upsilon^{t} \mu_{\Upsilon, t}}+a\left(u_{t}\right) \Upsilon^{-t} \bar{K}_{t}+\bar{D}_{t}^{M}+\bar{C}_{t}^{e}
$$

where $C$ is households' consumption, $G$ public consumption, $\frac{l_{t}}{\Upsilon^{t} \mu \Upsilon, t}$ households' investment in raw capital, $a\left(u_{t}\right) \Upsilon^{-t} \bar{K}_{t}$ for capital utilization costs (all these being standard, see Appendix for details), $\bar{D}_{t}^{M}$ monitoring costs, as a proportion of the mass of matched entrepreneurs, i.e

$$
\bar{D}_{t}^{M}=\mu G\left(\omega_{t}\right)\left(1+R_{t}^{k}\right) \frac{Q_{t-1} \bar{K}_{t}}{P_{t}}
$$

and, finally, where $\bar{C}_{t}^{e}$ is the aggregate non-survival payoff, in real terms, as

$$
\bar{C}_{t}^{e}=\frac{1-\gamma_{t}}{\gamma_{t}} \Theta \frac{\bar{N}_{t+1} \frac{m_{t}}{m_{t+1}}-\bar{W}_{t}^{e}-u_{t}^{e} D_{t}^{S}}{P_{t}}
$$

Indeed, we consider the aggregate level of entrepreneurial assets, hold by matched entrepreneurs, in nominal terms, at the end of period $t,\left[1-\Gamma_{t-1}\left(\bar{\omega}_{t}\right)\right] R_{t}^{k} Q_{K, t-1} \bar{K}_{t}$, which is equal to $\left(\bar{N}_{t+1} \frac{m_{t}}{m_{t+1}}-\bar{W}_{t}^{e}\right) / \gamma_{t}$ by (22), net of transfers $u_{t}^{e} D_{t}^{S}$ to searching entrepreneurs. A fraction $\left(1-\gamma_{t}\right)$ of it is hold by those who die, and a fraction $\Theta$ itself consumed. Equivalently, at the individual (matched entrepreneur) level, $C_{t}^{e}=\bar{C}_{t}^{e} / m_{t}$ is thus the non-survival payoff entering the Bellman equations, from (9) onward.

The total number of matched entrepreneurs evolves over time as

$$
m_{t+1}=\gamma_{t}\left\{\left[1-F_{t-1}\left(\bar{\omega}_{t}\right) s^{c}\right] m_{t}+z^{c}\left(u_{t}^{e}\right)^{\alpha^{c}}\left(u_{t}^{b}\right)^{1-\alpha^{c}}\right\}
$$


i.e it is equal, at the beginning of period $t+1$, to the sum of matched entrepreneurs that did not separate in period $t$ and new matches in period $t$ from equation (2).

Net firm creation is thus given by

$$
n e t_{t} \equiv m_{t+1}-m_{t}=\underbrace{\gamma_{t} z^{c}\left(u_{t}^{e}\right)^{\alpha^{c}}\left(u_{t}^{b}\right)^{1-\alpha^{c}}}_{\text {gross firm creation }}-\underbrace{\left[\left(1-\gamma_{t}\right)+\gamma_{t} F_{t-1}\left(\bar{\omega}_{t}\right) s^{c}\right] m_{t}}_{\text {gross firm destruction }}
$$

where, as of time $t$, 'gross firm creation' is the flow of new matches during period $t$ which survive in $t$, and 'gross firm destruction' is the sum of dying firms, with probability $\left(1-\gamma_{t}\right)$, and defaulting firms that separate, with probability $F_{t-1}\left(\bar{\omega}_{t}\right) s^{c}$.

\subsection{Shocks}

As stated before, the full model is a general equilibrium DSGE model with infinitely-lived households - who own monopolistic intermediate producers, a competitive final good sector, and the banks -, as well as a public authority. While these formal parts are relegated to Appendix, we nevertheless list here all shocks to be included in the estimation (Section 3). They follow an autoregressive process of order 1 in logs as

$$
\log \left(x_{t} / x\right)=\rho_{x} \log \left(x_{t-1} / x\right)+\epsilon_{x, t}
$$

where $\rho_{x}$ is the autocorrelation and $\sigma_{x}^{2}$ the variance of a shock $x$, and include

- The above mentioned risk shock, with unanticipated and anticipated components;

- A consumption preference shock;

- A price and a wage markup shocks;

- An investment price and an investment efficiency shocks;

- A persistent and a temporary technology shocks;

- An equity shock;

- A government spending shock; 
- A monetary policy (risk-free rate) shock.

For these shocks, the mean will be calibrated but their variance and autocorrelation estimated. In addition, we consider a (calibrated) target inflation rate shock and an (estimated) measurement error on entrepreneurs' net worth.

\section{Estimation}

We especially aim at quantifying $(i)$ the importance of credit search frictions and $(i i)$ the sources of fluctuations in firm creation, including uncertainty shocks.

\subsection{Bayesian estimation methodology}

The model is estimated with Bayesian methods, which may be decomposed into three steps. First, the linearized version of the model is solved, so that the dynamics are described in a statespace representation. Second, the posterior kernel of the model (i.e. the product of the prior densities and the likelihood of the model obtained by running a Kalman filter) is evaluated and maximized. Third, once the posterior mode is found, we obtain the entire posterior distribution by implementing a Metropolis-Hastings algorithm with 500,000 replications. For more details on the Bayesian methods, see the reviews by An and Schorfeide (2007) and Fernandez-Villaverde et al. (2016). We use the Dynare software package by Adjemian et al. (2011) to simulate and estimate the model.

\subsection{Data}

We use quarterly observations on 12 variables over the period 1980-Q1 to 2016-Q4. This first includes eight main macroeconomic aggregates, namely the growth rates of real GDP per capita, real consumption per capita, real investment per capita, price deflator (inflation), wages, the 
price of investment, the level of hours worked, and the short-term risk-free interest rate which is either the effective federal funds rate when different from zero or Wu and Xia (2016)'s shadow rate during the zero lower bound period. ${ }^{14}$ Second, three financial variables include the growth rate of credit, the stock market capitalization (as a proxy of entrepreneurial net worth), and the credit spread between the yields of the BAA corporate bonds and the 10-year government bonds. Finally, we construct a series of firm creation from 1980 to today by combining two series on establishment births: new business incorporations from the Survey of Current Business, which ends in 1995, and the recent series of establishment births provided by the Bureau of Labor Statistics, which starts in $1992 .{ }^{15}$ This way, we are able to study firm dynamics on a long period, including the last recession. ${ }^{16}$ See Appendix 1 for more data details and sources.

Thus, we define $\mathrm{DATA}_{t}$ as

$$
\operatorname{DATA}_{t}=\left[\begin{array}{c}
\Delta \text { log GDP }_{t} \\
\Delta \log \text { Consumption }_{t} \\
\Delta \log \text { Investment }_{t} \\
\Delta \log \text { Inflation }_{t} \\
\Delta \log \text { InvestmentPrice }_{t} \\
\Delta \log \text { Wage }_{t} \\
\log \text { Hours }_{t} \\
\text { R }_{t} \\
\text { CreditSpread }_{t} \\
\Delta \log \text { Credit }_{t} \\
\Delta \log \text { NetWorth }_{t} \\
\log \text { Creation }_{t}
\end{array}\right]
$$

and the set of observable variables as the deviation of $\mathrm{DATA}_{t}$ from its empirical mean, i.e

$$
\mathrm{OBS}_{t}=\mathrm{DATA}_{t}-\overline{\mathrm{DATA}}
$$

\footnotetext{
${ }^{14}$ We also run estimations from 1980-Q1 to 2006-Q4 only. Results are discussed in Section 4.4.

${ }^{15}$ An establishment is a single physical location where business is conducted or where services or industrial operations are performed.

${ }^{16}$ Many papers use a data sample either ending in the mid-1990s ( Lewis and Poilly (2012), Lewis and Stevens (2015), Bergin et al. (2018)), or starting in the mid-1990s (Poutineau and Vermandel (2015)).
} 


\subsection{Calibrated parameters}

Table 1 summarizes parameters which are hold constant during the estimation. ${ }^{17}$ Most values follow DSGE standards over our estimation period (1980-2016).

Table 1 - Calibrated parameters (quarterly)

\begin{tabular}{ccc}
\hline Households & Curvature of disutility of labor & \\
$\sigma_{L}$ & Capital depreciation rate & 1 \\
$\delta$ & Tax rate on consumption & 0.025 \\
$\tau^{c}$ & Tax rate on capital income & 0.047 \\
$\tau^{k}$ & Tax rate on labor income & 0.32 \\
$\tau^{\prime}$ & Capital share of output & 0.241 \\
Production sector & Wage markup & \\
$\alpha$ & Technology growth, investment goods & 0.4 \\
$\lambda_{w}$ & Price markup, intermediate good sector (steady-state) & 1.05 \\
$\gamma$ & Investment good technology shock (steady-state) & 1.20 \\
$\lambda_{f}$ & Technology growth, final good sector (steady-state) & 1.004 \\
$\mu_{\Upsilon}$ & Transfer received by new entrepreneurs & 0.005 \\
$\mu_{z}$ & Share of assets consumed by entrepreneurs & 0.005 \\
Entrepreneurs & Elasticity of new matches to unmatched entrepreneurs & 0.5 \\
$w^{e}$ & Total population of banks (matched and unmatched) & 2 \\
$\Theta$ & Survival rate of entrepreneurs (steady-state) & 0.985 \\
$\alpha^{c}$ & & \\
$p o p^{b}$ & Monetary policy interest rate (steady-state) & 0.0113 \\
$\gamma$ & Target inflation (gross rate) (steady-state) & 1.00595 \\
Public authority & Government expenditure to GDP ratio (steady-state) & 0.2 \\
$R$ & & \\
$\pi^{t a r g e t}$ & & \\
$G / Y$ & &
\end{tabular}

For households, the inverse of the Frisch elasticity of labor supply $\sigma_{L}$ is fixed to 1 , the depreciation rate of physical capital $\delta$ is set to $2.5 \%$ per quarter, while tax rates follow CMR for the US economy.

The production sector is composed of both intermediate and final good producers (Appendix). The labor market markup is set to 1.05 and the intermediate good price markup to 1.2 (Chris-

\footnotetext{
${ }^{17}$ This includes the means of the exogenous shock processes presented in Section 2.5. However, both the standard deviations and autocorrelation coefficients of these processes will be estimated (see Table 2). Means not reported here are either normalized to unity (temporary technology shock, consumption preference shock, investment efficiency shock) or deducted from posterior means (risk shocks).
} 
tiano et al. (2005)), while the capital share $\alpha$ is set to 0.40 in order to obtain an investment to GDP ratio close to its empirical value. The annual growth rate $\mu_{z}$ of the unit-root technology shock and annual growth rate $\Upsilon$ of investment-specific technological change are respectively set to 1.65 percent and 1.70 percent annually, in order to match the mean growth rates of real GDP per capita and price of investment goods on our sample.

As for entrepreneurs, $\alpha^{c}$ is the elasticity of the matching function (1), set up to half symmetrically. As bankers cannot enter or exit from the credit market, their total population must also be fixed arbitrarily, here to $p o p^{b}=2$ (while the number of lending relationships take a prior value of 1 in Table 2). Finally, both the transfer from households and the non-survival consumption, respectively $w^{e}$ and $\Theta$, are set to a computationally negligible value of 0.005 , while the steady-state survival rate $\gamma$ of entrepreneurs is 0.985 , following CMR.

Finally, the monetary policy risk-free rate is $4.6 \%$ annually on our sample, and we set the target inflation rate $\pi$ to $2.4 \%$ annually, such that households' discount factor is 0.9987 .

\subsection{Estimated parameters: priors and posteriors}

Table 2 reports priors and estimated posteriors together with their $90 \%$ confidence intervals. Our general equilibrium includes three types of frictions - real, nominal, and financial -, such that we estimate parameters in each one of these categories. Real friction parameters include the degree of habit formation and the curvatures of the investment adjustment and utilization cost technologies. Nominal friction parameters relate to price and wage stickiness, with Calvo probabilities and degrees of price indexation in particular. They also include the respective weights of output and inflation gaps in the monetary policy Taylor-type rule. Priors are aligned with the literature on Bayesian estimation of business cycle models, e.g Smets and Wouters $(2003,2007)$. 


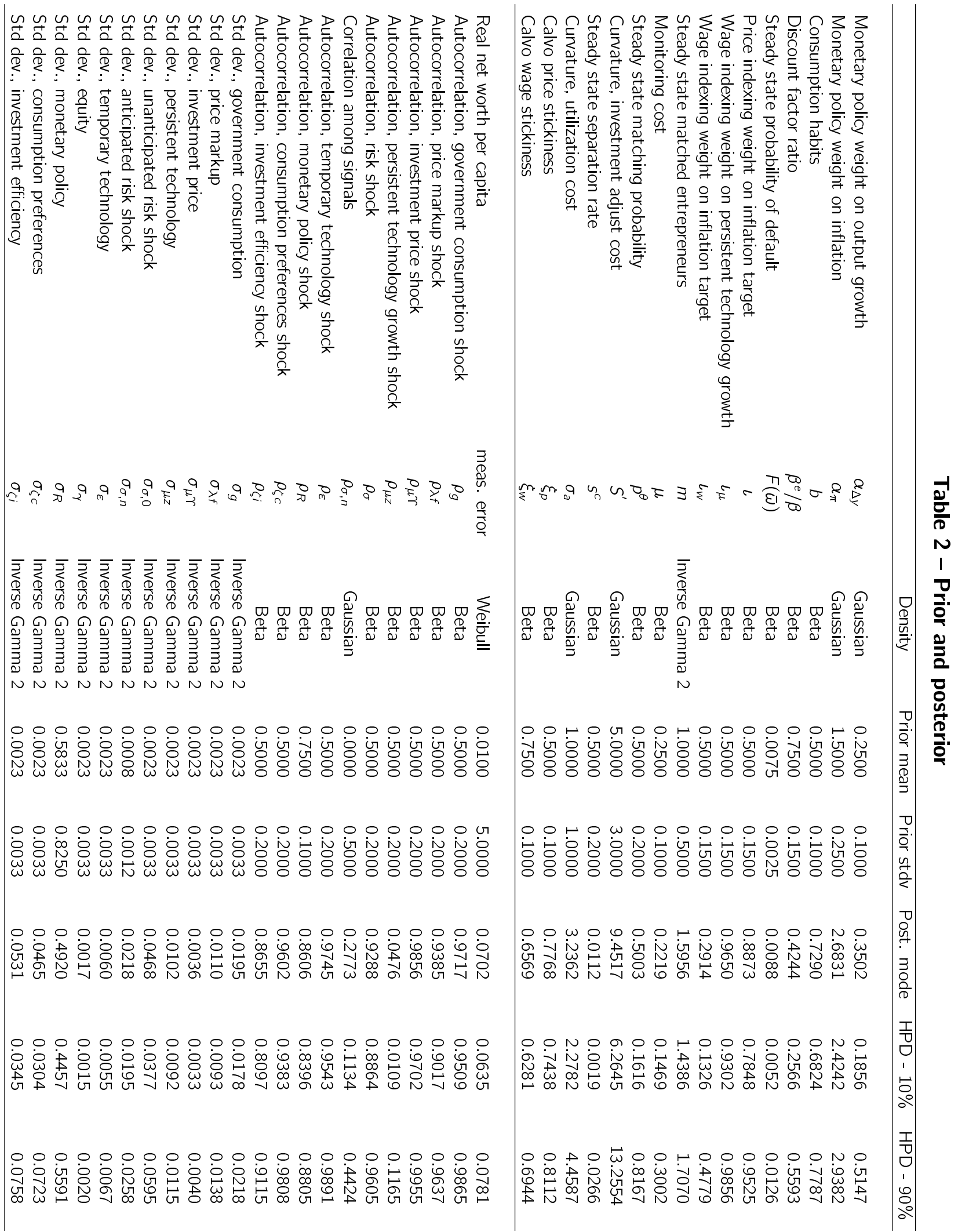


Financial friction parameters relate to both the CSV contract and credit search activities. The former includes the estimation of the monitoring cost and the rate of default on loans, for which we use the same priors as in CMR. In contrast, credit search parameters have not yet been estimated with Bayesian techniques, and very little information is known from the empirical banking or macroeconomic literatures in general either. ${ }^{18}$ We therefore assume diffuse priors in order to let the data "speak" by themselves. In particular, both the matching probability $p^{\theta}$ of a searching entrepreneur and the separation probability $s^{c}$ of a defaulting matched entrepreneur can vary between 0 and 1 , by definition. Therefore, we set both prior means to 0.5 and allow for large prior standard deviations of 0.2. Similarly, we set the ratio of entrepreneurs' to households' discount factors to 0.75, which is lower than Carlstrom and Fuerst (1997)'s 0.95 for instance, to allow for a large variance. Finally, the prior mean for the mass $m$ of matched entrepreneurs is arbitrarily normalized to unity.

Let us now turn to posterior values. Real and nominal parameters are in line with the literature and therefore not discussed here. As far as financial parameters are concerned, the CSV posteriors, $F$ and $\mu$, also result in values consistent with the literature. For instance, Carlstrom and Fuerst (1997) find a range of 0.2 to 0.36 for direct monitoring costs. Our value of $\mu$ at 0.22 falls down this range, but at the lower hand, suggesting that the search friction may susbstitute part of the CSV problem in our model credit market. Re-estimating our model absent of search friction, we indeed obtain $\mu=0.26$ (see Section 4). Last but not least, as for credit search parameters, let us first notice the very different results for the two probabilities, $p^{\theta}$ and $s^{c}$. On the one hand, the matching probability $p^{\theta}$ is very close to its prior value, together with a very wide confidence interval from 0.16 to 0.82 , suggesting that the data at hand is not particularly informative on the value of this specific parameter. On the other hand, the separation proba-

\footnotetext{
${ }^{18}$ For instance, Levenson and Willard (2000) argue that the duration of the credit application process is a key to credit rationing, yet do not provide an average duration of credit search.
} 
bility $s^{c}$ turns to a posterior value of $1 \%$, together with a narrow confidence interval between $0.2 \%$ and $3 \%$. This implies a duration of bank-entrepreneur lending relationships of 16 years on average in our sample. Finally, the ratio of entrepreneurs' to households' discount factors is 0.42 . This value might seem low, yet it is consistent with entrepreneurs' forward-looking behavior in the presence of search on the credit market. Indeed, unlike the canonical BGG-CMR model where the CSV contract is purely static, search frictions make it dynamic here. This is because entrepreneurs know that the default choice today will affect their chance of staying in a lending relationship tomorrow. Hence, we get a positive discount factor, even though not as high as for households.

Combining the posterior results with steady-state values of endogenous variables, let us now give a feel for the size of credit search frictions in the economy. First, the ratio of total search costs over entrepreneurial periodic income (see equation (16)) is $0.66 .{ }^{19}$ In order words, an average entrepreneur in our sample pays two third of a quarterly income over the search for its lending relationship. Finally, as we provide a joint estimation of both CSV and credit search frictions, we find that aggregate search costs represent $5.4 \%$ of output whereas aggregate monitoring costs represent $0.4 \%$ of output, on average per period. Hence, credit search frictions seem to be particularly sizeable relative to the traditional CSV problem. However, this figure should be interpreted carefully because of various transfers between households and entrepreneurs. At the aggregate level, the consumption of entrepreneurs represent less than $1 \%$ of final good.

\subsection{Effects of an uncertainty shock}

Figure 3 plots Bayesian Impulse Response Functions of selected variables to an uncertainty shock. The shock increases the cross-sectional dispersion of entrepreneurs' productivity, making

\footnotetext{
${ }^{19}$ The value of the periodic search cost $d^{s}$ is not directly estimated, hence not in Table 1 , but deducted from the posterior values of other parameters. In the baseline estimation, this is 3.13.
} 
the CSV problem more severe. In turn, the risk premium goes up to ensure the participation of bankers. As a consequence, the credit spread increases and the demand for credit falls, leading to a macroeconomic downturn, characterized by a fall in investment and production. In terms of firm dynamics, some entrepreneurs prefer to stay idle rather than searching for a bank as rising uncertainty deteriorates their potential profits, so that we observe a clear decrease in firm creation on impact. On the other hand, the loan default rate increases in uncertainty, and therefore so does firm destruction. The combination of lower creation and higher destruction contributes to a persistent decline in the number of productive firms ('matched entrepreneurs').
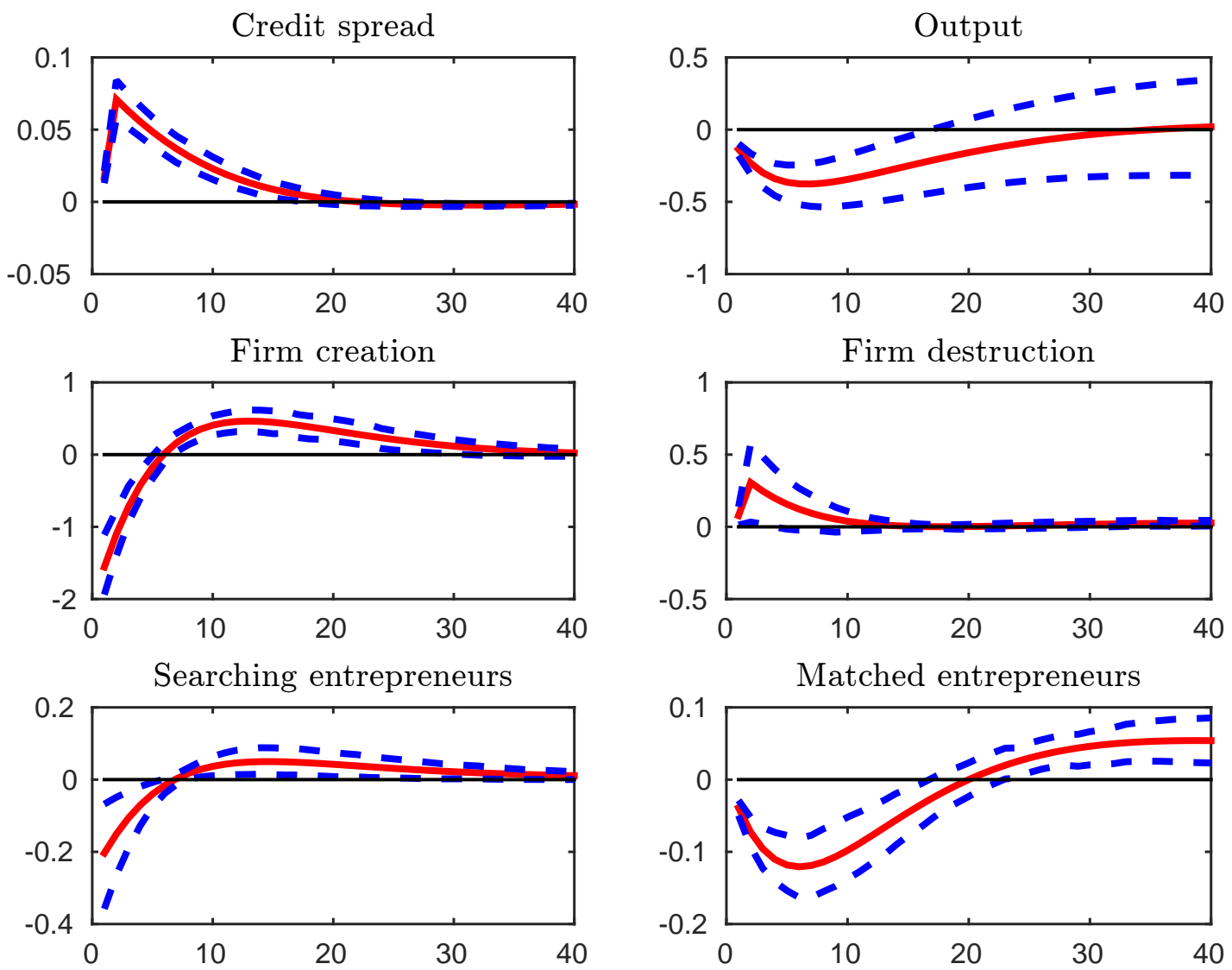

Figure 3 - Bayesian impulse response functions to a positive uncertainty shock, with highest posterior density interval at $\mathbf{9 0 \%}$, computed from 500,000 draws from the posterior distribution. Vertical axis in log-deviation, in percentage.

In order to explicit further the mechanism at play in our model, let us here recall the en- 

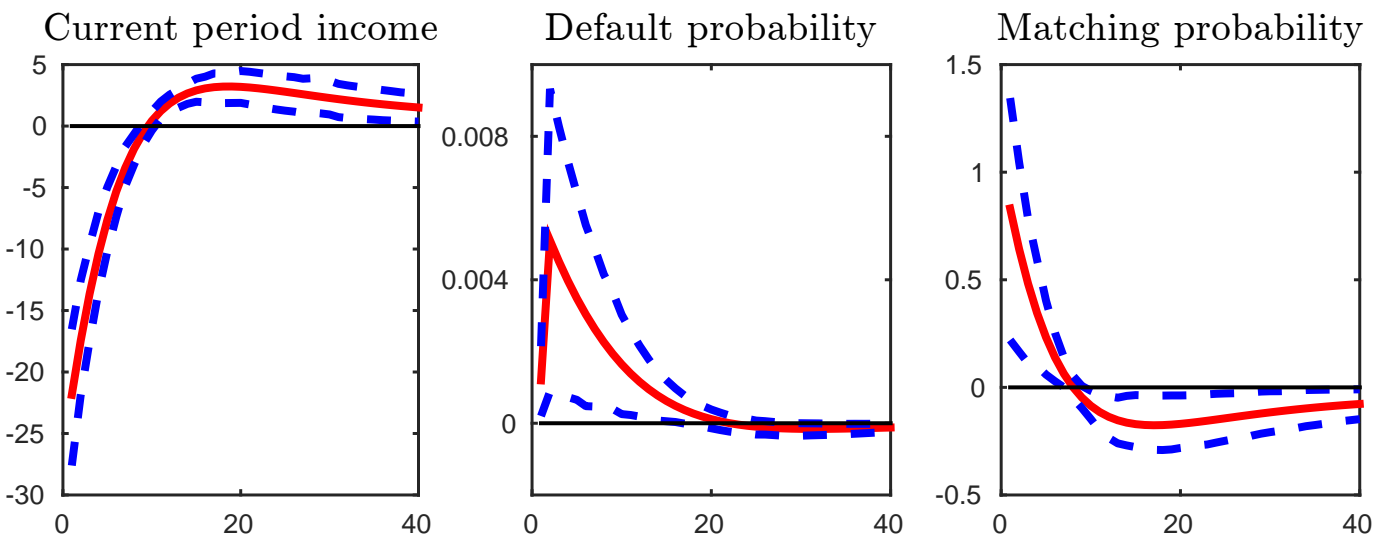

Figure 4 - Bayesian impulse response functions to a positive uncertainty shock, with highest posterior density interval at $\mathbf{9 0 \%}$, computed from 500,000 draws from the posterior distribution. Vertical axis in log-deviation, in percentage.

trepreneurs' equilibrium condition under free entry (16) as

$$
\begin{aligned}
& D^{S} / \underbrace{p_{t}^{\theta}}_{\text {Matching probability }}=\beta^{e} \gamma_{t} \mathrm{E}_{t}\{\overbrace{\left[1-\Gamma_{t}\left(\bar{\omega}_{t+1}\right)\right] R_{t+1}^{k} Q_{K, t} K_{t+1}}^{\text {Current period income }}+\overbrace{\left(1-\gamma_{t+1}\right) P_{t+1} C_{t+1}^{e}}^{\text {Non-survival payoff }} \\
& +\overbrace{[1-\underbrace{F_{t}\left(\bar{\omega}_{t+1}\right)}_{\text {Default probability }} s^{c}]}^{\text {Probability of staying matched next period }} \underbrace{D^{S} / p_{t+1}^{\theta}}_{\text {Continuation value }}\}
\end{aligned}
$$

On the right-hand side, a risk shock first decreases the entrepreneur's current period income. As the probability of loan default increases, the entrepreneur's share $\left(1-\Gamma_{t}\left(\bar{\omega}_{t+1}\right)\right)$ of the contract decreases. From households' investment decisions, the return on capital $R_{t+1}^{k} Q_{K, t} K_{t+1}$ also decreases, such that the whole first term in (29) goes down, as illustrated in the first cell of Figure 4. Then, the increase in default probability also generates separation of some lending relationships, by assumption. Since searching for a new bank is costly, while entrepreneurial activity pays less, many entrepreneurs decide to exit (or not to enter) the market, via the free 
entry condition. Yet, as the credit market congestion declines, the few remaning entrepreneurs have some higher probability to find a lending relationship ( $p^{\theta}$ increases), as shown in the last cell of Figure 4.

Overall, uncertainty shocks participate not only in the countercyclicality of credit spread, but also in the cyclical patterns of firm creation (procyclical) and firm destruction (countercyclical) observed in the data when search is at play in the model.

\subsection{Relative contributions of shocks}

Table 3 reports the contribution of shocks to the variance of the observed variables at business cycle frequencies. We find that uncertainty shocks are an important contributor to business cycles, in line with a growing literature, including Bloom (2009), Fernández-Villaverde et al. (2015), Leduc and Liu (2016), or Basu and Bundick (2017), just to cite a few. First, as far as financial series are concerned, risk shocks are clearly the main contributor to the variance, whether for the credit spread (96.4\%), but also net worth $(52.7 \%)$ and credit growth (44\%). Second, turning to standard macroeconomic variables, risk shocks are also an important source of fluctuations, sometimes coming into second position when not in first. Notice in particular the contribution of risk shocks for the growth rates of real GDP, investment, hours worked, and the risk-free rate. Exceptions are consumption and wage growth rates, whose fluctuations are very little driven by uncertainty shocks. Last but not least, business cycle fluctuations in firm creation are also primarily driven by uncertainty shocks (49.6\%), just before investment efficiency shocks (41.27\%).

Let us now focus on the U.S Great Recession, a particularly interesting episode in the sample. In Figure 5, we show the contribution of selected shocks to the historical variance of credit spread, growth rate of real GDP, and flows of firm creation, in particular. Consistently with numerous 


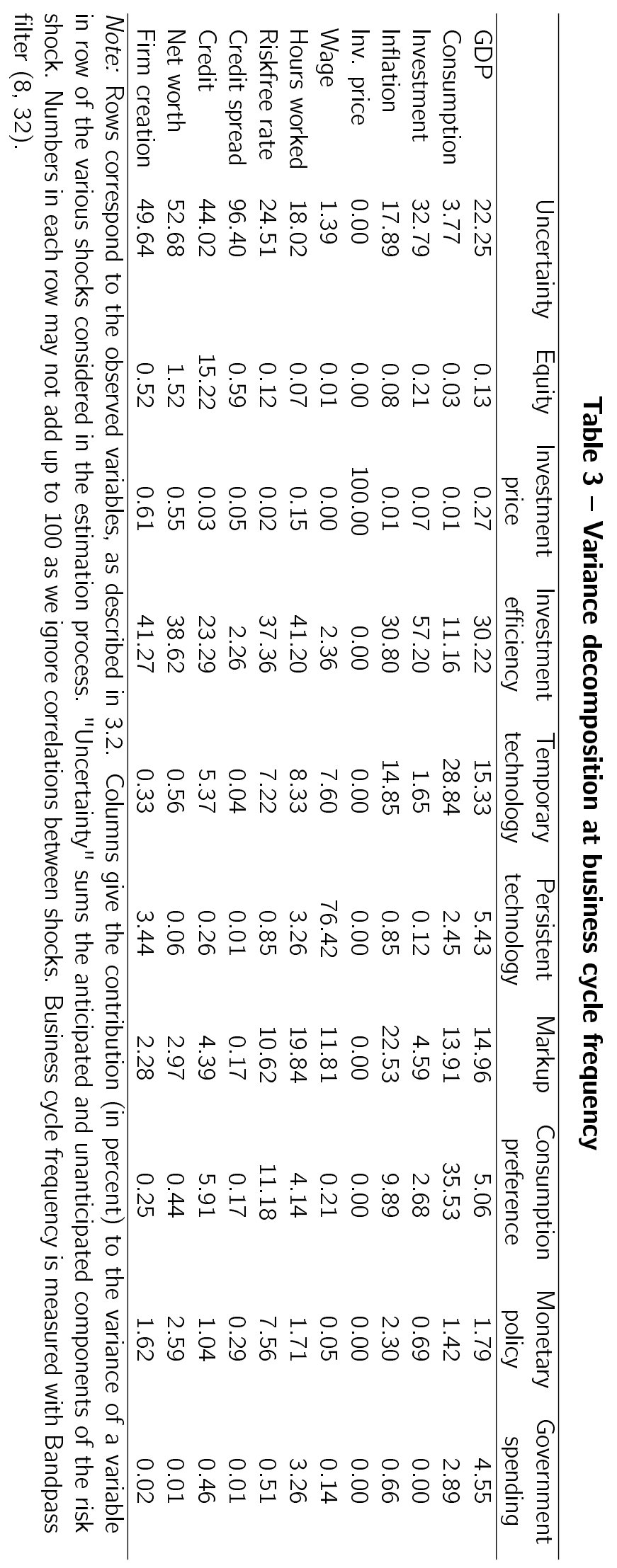



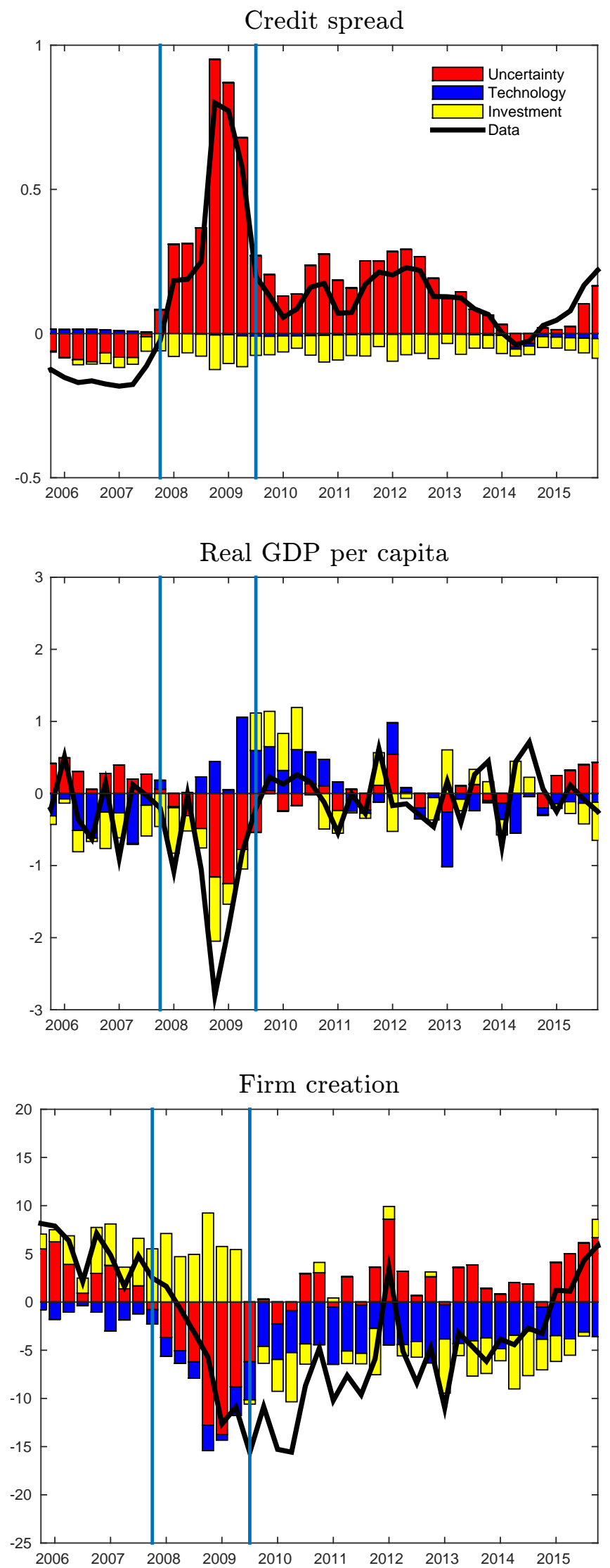

Figure 5 - Historical data and historical contribution of selected shocks to credit spread (in deviation of percentage points from average and steady-state), output growth and firm creation (in log, percentage deviation from average and steady-state) during the Great Recession. "Uncertainty" stands for the risk shock (both anticipated and unanticipated components); "Technology" stands for the technology shock (both persistent and temporary components); "Investment" stands for the investment efficiency shock. 
narratives, uncertainty shocks are found to play a key role during this particular episode. The rise in uncertainty accounts for a sharp fall in production and investment in 2008 and 2009 in particular. When it comes to firm creation, uncertainty shocks seem to cause the bulk of the sharp initial drop, but much less in the aftermath of the crisis as productivity and investment efficiency shocks become more important. However, uncertainty shocks also generate a peak in firm destruction and a very sluggish recovery in the total number of firms in the economy (Figure 2.2).

A widespread narrative of the Great Recession, and of US business cycles in general, is the key role of the housing market. Liu et al. (2013) build a model where land is used as a collateral by financially constrained firms. Then, a fall in house prices deteriorates the ability of these firms to reimburse their loans, triggering a recession. As there is no housing market in our model, it is worth noting that uncertainty shocks may capture part of the fluctuations induced by housing market shocks. Indeed, uncertainty (i.e higher cross-sectional productivity of firms) increases the loan default probability and thereby the credit spread in our setup. Hence, both mechanisms result in a tightening of credit conditions that is at the core of the Great Recession.

\section{Discussion}

In this Section, we further discuss the role of three key elements of our model, namely $(i)$ the credit search friction, (ii) risk shocks, and (iii) the CSV problem, by comparing our economy to alternative specifications where these are removed one after another. Then, we provide sectoral evidence on the link between uncertainty and firm dynamics. 


\subsection{The role of the credit search friction}

Absent of search friction, the CSV problem remains the only friction at play on the credit market, as in CMR. In practice, this is obtained when the number $m$ of matched entrepreneurs is hold constant in the economy, new born firms are directly matched, and the separation rate $s^{c}$ is equal to 0 in the financial contract.
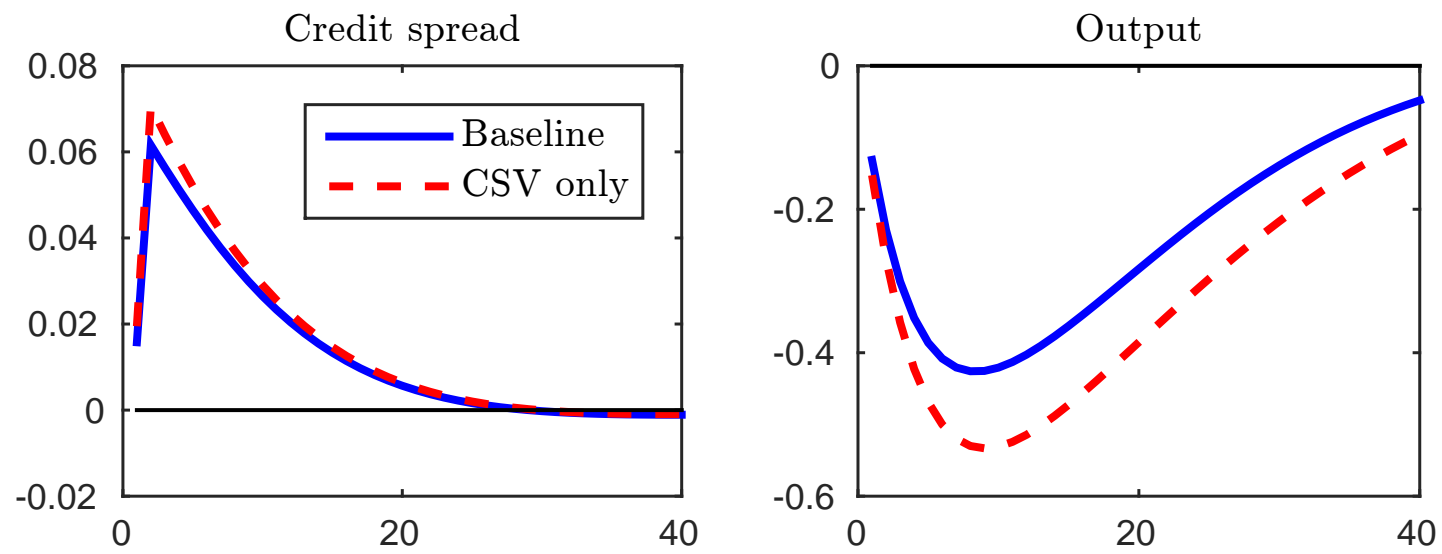

Figure $\mathbf{6}$ - Impulse response functions to a positive uncertainty shock. Vertical axis in logdeviation, in percentage. The "CSV only" case use posterior parameters reported in Table 2.1, whereas the baseline posterior parameters are those of Table 2 except for the size and the persistence of the uncertainty shock process which here take the values given in Table 2.1 for both cases.

Figure 6 compares responses to an uncertainty shock in our baseline versus in the economy with CSV only. ${ }^{20}$ Both the credit spread and ouptut respond less to the shock in our baseline as compared to the CSV only case. In other words, the credit search friction tends to dampen aggregate fluctuations as compared to a similar economy but with CSV only. This is because, in response to a risk shock, the increase in the loan default rate is less important when default is associated with a positive probability for matched entrepreneurs to lose their lending relationship,

\footnotetext{
${ }^{20}$ Unlike Figure 3 , there is no firm dynamics in the model without search friction, by definition.
} 
given that searching again for a new one is costly. Therefore, a lower increase in defaults implies less monitoring and thus a lower increase in the risk premium. In turn, output decreases less in our model as compared to the CSV only case.

Furthermore, the variance decomposition in the CSV only case is reported in Table 2.2. Here, the role of the risk shock as a driver of fluctuations in the main macro-finance variables increases, as compared to Table 3. For instance, it accounts for $23 \%$ of GDP growth, versus $22 \%$ in the baseline, for $43 \%$ of investment versus $33 \%$ in the baseline, for $47 \%$ of credit versus $44 \%$ in the baseline, and for $79 \%$ of net worth versus $53 \%$ in the baseline. This may again suggest that credit search mitigates responses of the economy to fluctuations in risk shock. However, it is worth pointing out that there is no firm dynamics in the CSV only case and therefore estimation results can be affected.

\subsection{The role of risk shocks}

Let us now consider a scenario in which there is no risk shocks. Table 4 provides the variance decomposition for this economy. ${ }^{21}$ It turns out that the equity shock, i.e the shock on the exogenous survival rate $\gamma$ of entrepreneurs, now explains most of the variance of financial series - in particular total credit (84\%) and credit spread (78\%) -, while the main driver of most macroeconomic variables becomes the investment efficiency shock - in particular GDP (44\%), investment $(76 \%)$, hours worked $(52 \%)$, and interest rate $(35 \%)$. Firm creation is also now mostly driven by the investment efficiency shock (55\%), followed by the equity shock (29\%).

Hence the striking result here is that, without risk shocks, financial fluctuations, on the one hand, and macroeconomic fluctuations, on the other hand, seem to be driven by different exogenous sources. This suggests a disconnection between the financial and real spheres of the

\footnotetext{
${ }^{21}$ In addition, estimated values of structural parameters are reported in Table 2.3.
} 


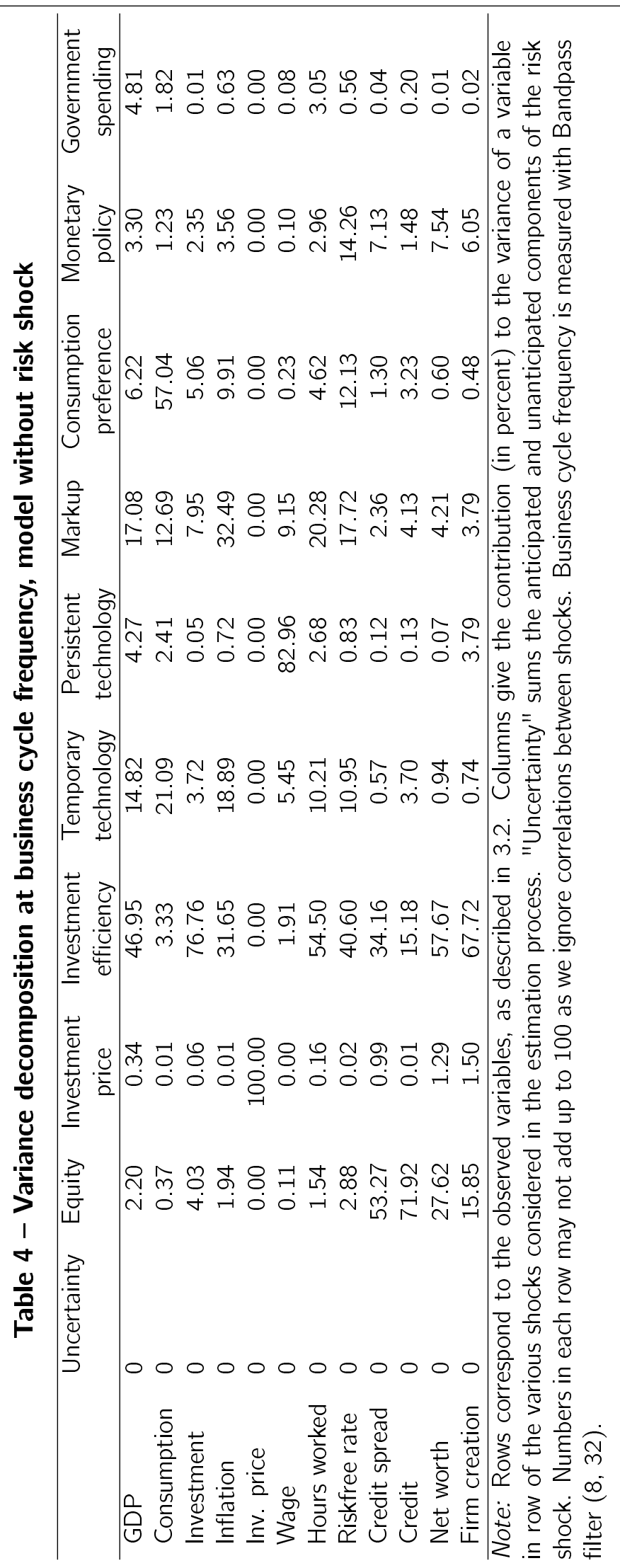


economy, which disappears when the risk shock comes into play. This result echoes CMR who show that risk shocks diminish the role otherwise played by equity and technology shocks. Previously, Gertler and Kiyotaki (2010) and Gertler and Karadi (2011) found that equity shocks can have important role during financial crisis by affecting the quantity of net worth in the hands of entrepreneurs, but unlike risk shocks, it has the counterfactual implication that credit is countercyclical. Justiniano et al. (2010) emphasized the role of technology shocks in the production of installed capital (marginal efficiency of investment). But here again, their importance is reduced when risk shocks and financial observations are also included in the estimation.

More generally, we thus contribute to the growing literature showing that risk shocks are important for the quantitative estimation of DSGE models with financial frictions. Indeed, before the Great Recession, canonical macroeconomic models did not include much of the early financial friction literature. A reason for that could have been the quantitatively disappointing results of estimated versions of the macro-finance models existing at the time, absent of the risk shock. For instance, Meier and Müller (2006) concluded that "the financial accelerator seems less important that we would have conjectured" and Christensen and Dib (2008) that "the importance of the financial accelerator for output fluctuations is relatively minor." However, the introduction of financial shocks has later revived the importance of financial frictions in DSGE models. These include CMR's risk shocks or Jermann and Quadrini (2012) among many others.

\subsection{The role of the monitoring cost}

Here, we compare our baseline economy to a case in which the monitoring cost $\mu$ is set to a negligible value. Macro-financial variables react much less in response to a risk shock when monitoring costs are low, as illustrated in Figure 7 (first line). This is the standard financial accelerator mechanism of the CSV contract. As far as firm dynamics are concerned (second and third lines), the responses seem very similar in both cases. However, this is due to two opposite 

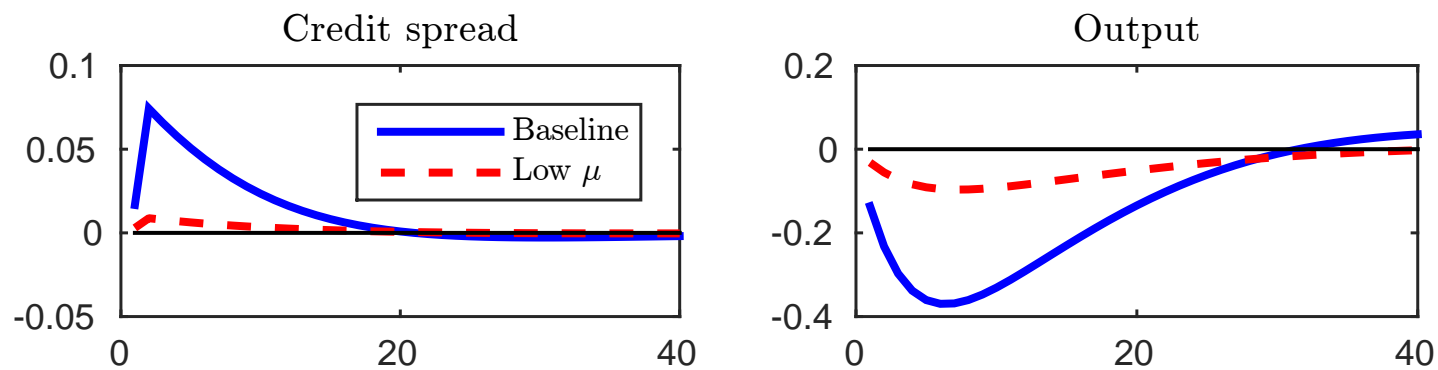

Firm creation

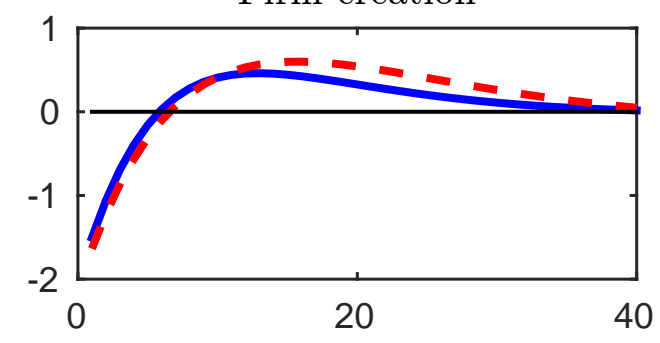

Firm destruction
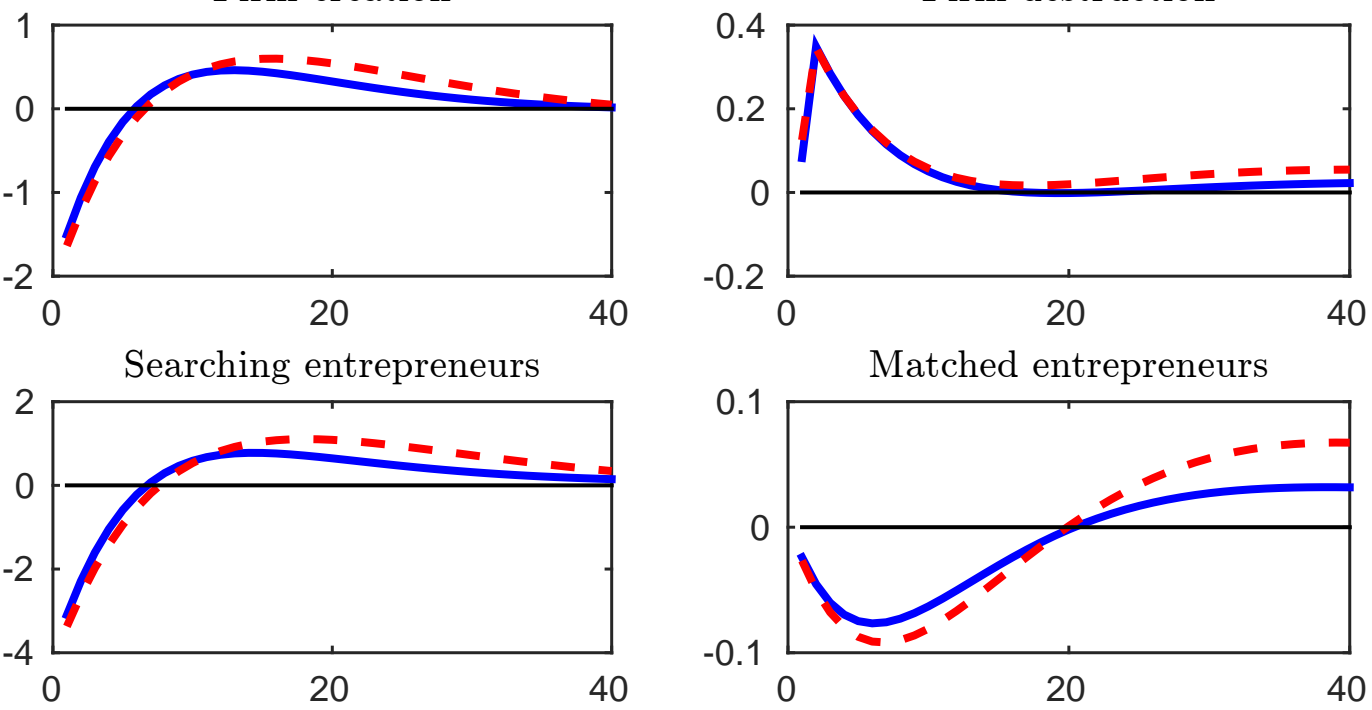

Figure 7 - Impulse response functions to a positive uncertainty shock. Vertical axis in logdeviation, in percentage. The baseline value for $\mu$ is 0.228 (posterior mean) and divided by 10 in the "low $\mu$ " case.

effects which offset one another. On the one hand, a lower contraction in output in associated with a lower fall in the value of entrepreneur production, which limits the fall in firm entry, when $\mu$ is low. On the other hand, the share of this value received by entrepreneurs (versus bankers) decreases more when $\mu$ is low, as compared to the baseline case (given the lower rise of credit spread, the fall in borrowing is less pronounced). Overall, the fall in entrepreneurial incomes induced by the risk shock is almost the same in the two cases. 


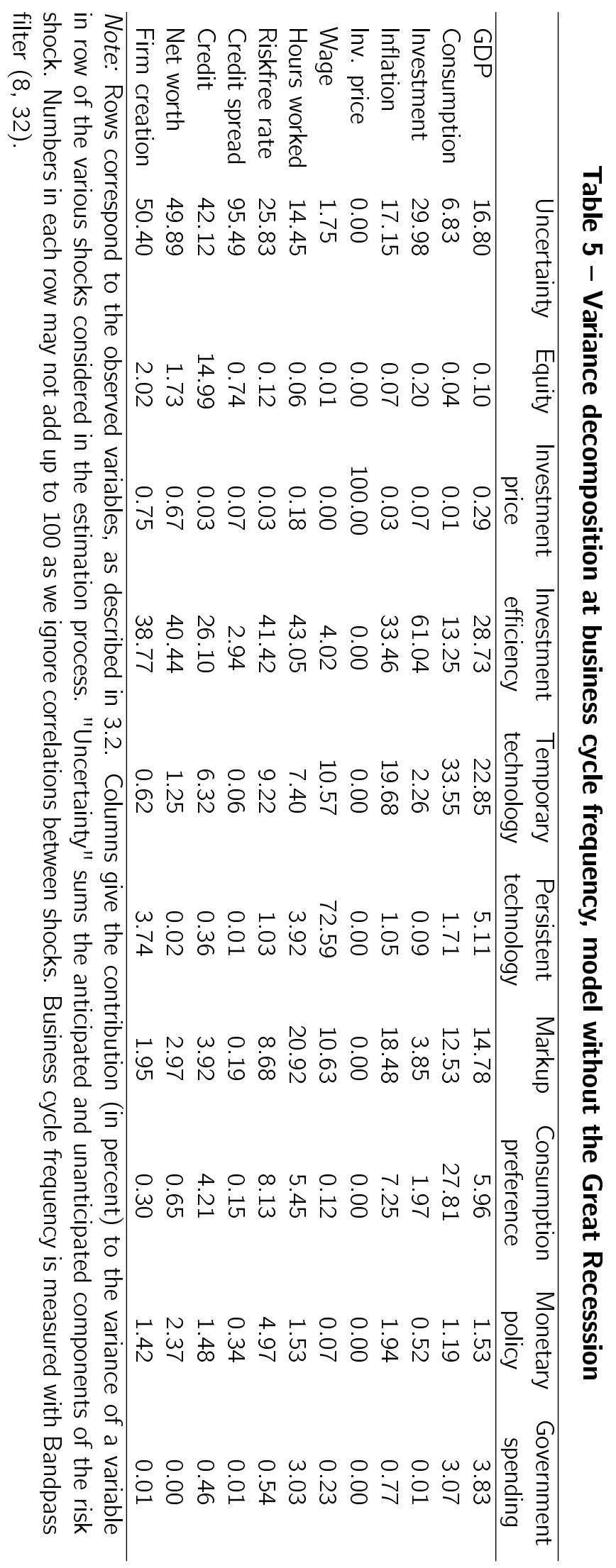




\subsection{Estimation on a shorter sample}

In this Section, we re-estimate the baseline model on a shorter sample, from 1980-Q1 to 2006Q4, i.e without the Great Recession. This first provides an alternative to using the shadow rate to account for the zero-lower bound period, as we do in the baseline estimation. Second, it allows to check whether or not the importance of uncertainty shocks is excessively driven by this particular episode in our sample.

The variance decomposition in Table 5 reveals that the overall importance of risk shocks is slightly reduced without the Great Recession, as expected. Yet, they still remain an important driver of aggregate (macroeconomic, financial, and firm dynamics) fluctuations. For instance, risk shocks account for $17 \%$ of output growth fluctuations when the Great Recession is absent of the sample against $22 \%$ in the baseline. For investment, this is $30 \%$ against $33 \%$. For firm creation, the difference is almost nil between the two estimation samples (50.4\% against $49.64 \%$ in the baseline). Estimated values of structural parameters (Table 2.4) are also relatively close to the baseline case.

\subsection{Additional evidence from sectoral-level data}

As a last exercise, we document the relationship between firm creation and uncertainty using external data at the sectoral level. Bloom et al. (2018) provide empirical evidence of countercyclical micro-level uncertainty, complementing earlier results for macro-level uncertainty (Bloom (2014)). In line with this analysis, we here aim at showing that the growth rate of firm establishments is negatively correlated with uncertainty.

On the one, we use SUSB (Statistics of U.S. Businesses) annual data tables by establishment industry, available since 1998 (US, 6-digit NAICS). As we do not have the flows of birth and death of establishments by industry, we directly compute the annual net growth rate of establishments. 


\begin{tabular}{|c|c|c|c|c|c|}
\hline . & (1) & $\begin{array}{c}\text { (2) } \\
\text { Establishme }\end{array}$ & $\begin{array}{l}\text { (3) } \\
\end{array}$ & (4) & $\begin{array}{c}\text { (5) } \\
\text { erms' growt }\end{array}$ \\
\hline Uncertainty & $\begin{array}{c}-0.020^{* * *} \\
(0.005)\end{array}$ & $\begin{array}{c}-0.017^{* * *} \\
(0.005)\end{array}$ & $\begin{array}{c}-0.018^{* * *} \\
(0.005)\end{array}$ & $\begin{array}{c}-0.012^{*} \\
(0.007)\end{array}$ & $\begin{array}{c}-0.012^{*} \\
(0.007)\end{array}$ \\
\hline Investment & $\begin{array}{c}0.001^{* *} \\
(0.0004)\end{array}$ & $\begin{array}{c}0.001^{* *} \\
(0.0003)\end{array}$ & $\begin{array}{c}0.006^{* * *} \\
(0.002)\end{array}$ & $\begin{array}{c}0.007^{* * *} \\
(0.002)\end{array}$ & $\begin{array}{c}0.008^{* * *} \\
(0.002)\end{array}$ \\
\hline Capital stock & $\begin{array}{l}-0.004 \\
(0.003)\end{array}$ & $\begin{array}{l}-0.004 \\
(0.003)\end{array}$ & $\begin{array}{c}-0.010^{* *} \\
(0.004)\end{array}$ & $\begin{array}{c}-0.012^{* * *} \\
(0.004)\end{array}$ & $\begin{array}{c}-0.013^{* * *} \\
(0.005)\end{array}$ \\
\hline Constant & $\begin{array}{c}-0.060^{* * *} \\
(0.010) \\
\end{array}$ & $\begin{array}{c}-0.037^{* * *} \\
(0.012) \\
\end{array}$ & $\begin{array}{c}-0.081^{* * *} \\
(0.030) \\
\end{array}$ & $\begin{array}{c}-0.063^{* *} \\
(0.030) \\
\end{array}$ & $\begin{array}{c}-0.083^{* *} \\
(0.033) \\
\end{array}$ \\
\hline Fixed Effect 'year' & no & yes & no & yes & yes \\
\hline Fixed Effect 'sector' & no & no & yes & yes & yes \\
\hline Observations & 749 & 749 & 749 & 749 & 749 \\
\hline $\mathrm{R}^{2}$ & 0.033 & 0.095 & 0.187 & 0.255 & 0.237 \\
\hline
\end{tabular}

On the other hand, industry-level uncertainty data has been computed in Bloom et al. (2018). More specifically, we use the standard-deviation of the monthly stock-returns of all CRSP (Center for Research in Security Prices) firms within the industry-year in the dataset. ${ }^{22}$ Eventually, we have a dataset of firms dynamics for 94 different sectors since 1999.

Our results are reported in Table 6. Each column reports a time-series ordinary least squares (OLS) regression point estimate (with standard error in parentheses) of establishments' growth rate on uncertainty. As expected, we find a significant negative relationship. This holds in the simple OLS case (1), but also with fixed effects by year (2) or by sector (3) or by year and by sector ((4) and (5)). In our regressions, we also include investment and real capital stock from the NBER-CES Manufacturing Industry Database $(1958-2009)^{23}$, to control for cyclical variations in the size and activity of the sectors. Such regressors are very often significant in all the different cases. Eventually, in (5), we replicate the same regression as in (4), but with firms' growth rate instead of establishments' growth rate. ${ }^{24}$ The correlation remains negative 22 So, for example, if 10 firms were in an industry then this would be the standard-deviation across the 120 months
$(12 * 10)$ of stock returns for that industry-year.
${ }^{23}$ Built by Randy Becker, Wayne Gray and Jordan Marvakov and available at
http://www.nber.org/data/nberces5809.html
${ }^{24}$ According to SUSB, a firm is a business organization consisting of one or more domestic establishments in the 
and significant.

\section{Conclusion}

This paper builds a general equilibrium model where the credit market is characterized by an interplay between two frictions. On the one hand, entrepreneurs must search for a lending relationship at a bank. On the other hand, an optimal debt contract involving monitoring costs (a costly state-verification contract). We find that search frictions increase the borrower's cost of default by impairing its long-run lending relationship. As a consequence, as an uncertainty shock hits, entrepreneurs tend to default more on their loans but less so when the search is at play. Therefore, the macro-financial effects of uncertainty shocks are dampened as compared to a searchless but otherwise identical economy. From the medium-scale DSGE Bayesian estimation on U.S data over the period 1980-2016, we show that uncertainty shocks are a prime contributor to business cycle fluctuations, not only for macro-financial aggregates but also for firm creation. The Great Recession is a particularly striking episode when risk shocks matter.

Further research could extend our analysis in several dimensions. For instance, transitory idiosyncratic shocks make all firms identical ex-ante here. A richer environment, with persistent idiosyncratic shocks, would be an interesting extension for firm heterogeneity. In particular, it could make the separation of lending relationships endogenous whereas it is only an exogenous fraction of defaulting entrepreneurs in our model. Moreover, banks could be given a more active role in the search process, or policy implications studied more explicitly. Finally, by considering the potential role of firm creation in innovation dynamics, we could investigate the link between the fall in firm creation during the Great recession and the subsequent deterioration in the productivity of factors in the final good and investment sectors.

same state and industry that were specified under common ownership or control. 


\section{References}

Adjemian, S., Bastani, H., Juillard, M., Mihoubi, F., Perendia, G., Ratto, M., and Villemot, S. (2011). Dynare: Reference manual, version 4.

An, S. and Schorfeide, F. (2007). Bayesian analysis of DSGE models. Econometric Reviews, 26:113-172.

Arseneau, D. M., Rappoport, D., and Vardoulakis, A. (2017). Private and Public Liquidity Provision in Over-the-Counter Markets. Finance and Economics Discussion Series 2017033, Board of Governors of the Federal Reserve System (U.S.).

Basu, S. and Bundick, B. (2017). Uncertainty shocks in a model of effective demand. Econometrica, 85(3):937-958.

Beaubrun-Diant, K. E. and Tripier, F. (2015). Search frictions, credit market liquidity and net interest margin cyclicality. Economica, 82(325):79-102.

Becsi, Z., Li, V. E., and Wang, P. (2013). Credit mismatch and breakdown. European Economic Review, 59:109-125.

Bergin, P. R. and Corsetti, G. (2008). The extensive margin and monetary policy. Journal of Monetary Economics, 55(7):1222-1237.

Bergin, P. R., Feng, L., and Lin, C.-Y. (2018). Firm entry and financial shocks. The Economic Journal, (128):510-540.

Bernanke, B. S., Gertler, M., and Gilchrist, S. (1999). The financial accelerator in a quantitative business cycle framework. In Taylor, J. B. and Woodford, M., editors, Handbook of Macroeconomics, volume 1 of Handbook of Macroeconomics, chapter 21, pages 13411393. Elsevier.

Bilbiie, F. O., Ghironi, F., and Melitz, M. J. (2012). Endogenous Entry, Product Variety, and 
Business Cycles. Journal of Political Economy, 120(2):304-345.

Bloom, N. (2009). The Impact of Uncertainty Shocks. Econometrica, 77(3):623-685.

Bloom, N. (2014). Fluctuations in uncertainty. The Journal of Economic Perspectives, 28(2):153-175.

Bloom, N., Floetotto, M., Jaimovich, N., Eksten, I. S., and Terry, S. J. (2018). Really Uncertain Business Cycles. Econometrica, 86(3):1031-1065.

Carlstrom, C. T. and Fuerst, T. S. (1997). Agency costs, net worth, and business fluctuations: A computable general equilibrium analysis. The American Economic Review, pages 893910.

Chamley, C. and Rochon, C. (2011). From search to match: when loan contracts are too long. Journal of Money, Credit and Banking, 43(s2):385-411.

Chodorow-Reich, G. (2014). The Employment Effects of Credit Market Disruptions: Firmlevel Evidence from the 2008-9 Financial Crisis. The Quarterly Journal of Economics, 129(1):1-59.

Christensen, I. and Dib, A. (2008). The Financial Accelerator in an Estimated New Keynesian Model. Review of Economic Dynamics, 11(1):155-178.

Christiano, L. J., Eichenbaum, M., and Evans, C. L. (2005). Nominal rigidities and the dynamic effects of a shock to monetary policy. Journal of Political Economy, 113(1):1-45.

Christiano, L. J., Motto, R., and Rostagno, M. (2014). Risk Shocks. American Economic Review, 104(1):27-65.

Clementi, G. L. and Palazzo, B. (2016). Entry, exit, firm dynamics, and aggregate fluctuations. American Economic Journal: Macroeconomics, 8(3):1-41.

Cooley, T. F. and Quadrini, V. (2001). Financial Markets and Firm Dynamics. American Economic Review, 91(5):1286-1310. 
Craig, B. R. and Haubrich, J. G. (2013). Gross loan flows. Journal of Money, Credit and Banking, 45(2-3):401-421.

Darmouni, O. (2016). The effects of informational frictions on credit reallocation. Working Paper, Princeton University.

Dell'Ariccia, G. and Garibaldi, P. (2005). Gross credit flows. The Review of Economic Studies, $72(3): 665-685$.

Den Haan, W. J., Ramey, G., and Watson, J. (2003). Liquidity flows and fragility of business enterprises. Journal of Monetary Economics, 50(6):1215-1241.

Fernández-Villaverde, J., Guerrón-Quintana, P., Kuester, K., and Rubio-Ramírez, J. (2015). Fiscal volatility shocks and economic activity. The American Economic Review, 105(11):33523384.

Fernandez-Villaverde, J., Rubio-Ramirez, J., and Schorfheide, F. (2016). Chapter 9 - solution and estimation methods for DSGE models. volume 2 of Handbook of Macroeconomics, pages $527-724$. Elsevier.

Gertler, M. and Karadi, P. (2011). A model of unconventional monetary policy. Journal of Monetary Economics, 58(1):17-34.

Gertler, M. and Kiyotaki, N. (2010). Financial Intermediation and Credit Policy in Business Cycle Analysis. In Friedman, B. M. and Woodford, M., editors, Handbook of Monetary Economics, volume 3 of Handbook of Monetary Economics, chapter 11, pages 547-599. Elsevier.

Gourio, F., Messer, T., and Siemer, M. (2016). Firm entry and macroeconomic dynamics: A state-level analysis. American Economic Review, 106(5):214-18.

Herrera, A. M., Kolar, M., and Minetti, R. (2011). Credit reallocation. Journal of Monetary Economics, 58(6):551-563. 
Hyun, J. and Minetti, R. (2014). Credit reallocation, deleveraging, and financial crises. Unpublished manuscript, Michigan State University.

Jaimovich, N. and Floetotto, M. (2008). Firm dynamics, markup variations, and the business cycle. Journal of Monetary Economics, 55(7):1238-1252.

Jermann, U. and Quadrini, V. (2012). Macroeconomic Effects of Financial Shocks. American Economic Review, 102(1):238-271.

Justiniano, A., Primiceri, G. E., and Tambalotti, A. (2010). Investment shocks and business cycles. Journal of Monetary Economics, 57(2):132-145.

Leduc, S. and Liu, Z. (2016). Uncertainty shocks are aggregate demand shocks. Journal of Monetary Economics, 82:20-35.

Levenson, A. R. and Willard, K. L. (2000). Do firms get the financing they want? measuring credit rationing experienced by small businesses in the us. Small Business Economics, 14(2):83-94.

Lewis, V. (2009). Business cycle evidence on firm entry. Macroeconomic Dynamics, 13(05):605624.

Lewis, V. and Poilly, C. (2012). Firm entry, markups and the monetary transmission mechanism. Journal of Monetary Economics, 59(7):670-685.

Lewis, V. and Stevens, A. (2015). Entry and markup dynamics in an estimated business cycle model. European Economic Review, 74:14-35.

Lewis, V. and Winkler, R. (2017). Government spending, entry and the consumption crowding-in puzzle. International Economic Review, 58(3):943-972.

Liu, Z., Wang, P., and Zha, T. (2013). Land-price dynamics and macroeconomic fluctuations. Econometrica, 81(3):1147-1184.

Meier, A. and Müller, G. J. (2006). Fleshing out the Monetary Transmission Mechanism: Output 
Composition and the Role of Financial Frictions. Journal of Money, Credit and Banking, pages 2099-2133.

Mortensen, D. T. and Pissarides, C. A. (1994). Job Creation and Job Destruction in the Theory of Unemployment. Review of Economic Studies, 61(3):397-415.

Petrosky-Nadeau, N. and Wasmer, E. (2013). The cyclical volatility of labor markets under frictional financial markets. American Economic Journal: Macroeconomics, 5(1):193-221.

Petrosky-Nadeau, N. and Wasmer, E. (2015). Macroeconomic dynamics in a model of goods, labor, and credit market frictions. Journal of Monetary Economics, 72:97-113.

Poutineau, J.-C. and Vermandel, G. (2015). Financial frictions and the extensive margin of activity. Research in Economics, 69(4):525-554.

Rocheteau, G., Wong, R., and Zhang, C. (2017). Lending Relationships, Banking Crises and Optimal Monetary Policies. Technical report.

Rossi, L. (2016). Productivity Shocks and Uncertainty Shocks in a Model with Endogenous Firms Exit and Inefficient Banks. DEM Working Papers Series 128, University of Pavia, Department of Economics and Management.

Schaal, E. (2017). Uncertainty and unemployment. Econometrica, 85(6):1675-1721.

Sette, E. and Gobbi, G. (2015). Relationship lending during a financial crisis. Journal of the European Economic Association, 13(3):453-481.

Smets, F. and Wouters, R. (2003). An estimated dynamic stochastic general equilibrium model of the euro area. Journal of the European Economic Association, 1(5):1123-1175.

Smets, F. and Wouters, R. (2007). Shocks and frictions in us business cycles: A bayesian dsge approach. The American Economic Review, 97(3):586-606.

Taylor, J. B. (2014). The Role of Policy in the Great Recession and the Weak Recovery. American Economic Review, 104(5):61-66. 
Townsend, R. M. (1979). Optimal contracts and competitive markets with costly state verification. Journal of Economic Theory, 21(2):265-293.

Wasmer, E. and Weil, P. (2004). The Macroeconomics of Labor and Credit Market Imperfections. American Economic Review, 94(4):944-963.

Wu, J. C. and Xia, F. D. (2016). Measuring the macroeconomic impact of monetary policy at the zero lower bound. Journal of Money, Credit and Banking, 48(2-3):253-291. 


\section{Appendix}

\section{Appendix}

\section{Data}

\section{A. Firm creation and destruction series}

The series of firm creations combine two sources from the US, chained and depicted in Figure 1.1 , as follows

- Creation (part 1): "New Business Incorporations" from the Survey of Current Business, 1996 (Table 13), FRED, available at https://fraser.stlouisfed.org. Monthly data from 1948M1 to 1994 M12. We construct a quarterly sample and divide by population.

- Creation (part 2): "Number of establishments births" (total private sector) from the Bureau of Labor Statistics, available at https://www.bls.gov. Data is quarterly and seasonally adjusted, we divide it by population.

For firm destructions, the source is the same as for firm creation (part 2), i.e

- Destruction: "Number of establishments births" (total private sector) from the Bureau of Labor Statistics, available at https://www.bls.gov. Data is quarterly and seasonally adjusted, we divide it by population.

- Firms: "Number of Private Sector Establishments" from the Bureau of Labor Statistics (see the table). We construct a quarterly sample and divide by population.

\section{B. Other series: Macroeconomic and financial variables}

All series are for the US, as follows 


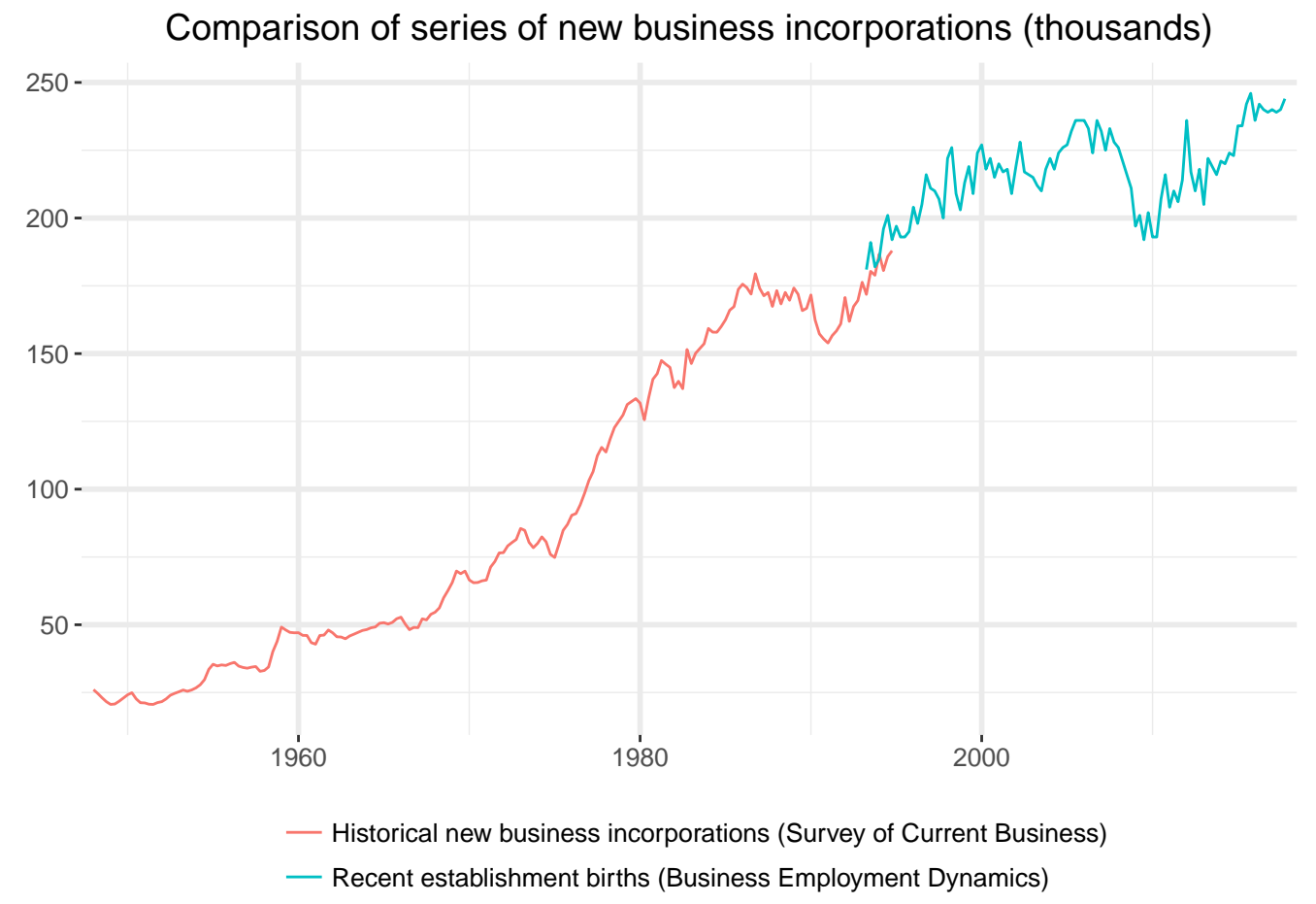

Figure 1.1 - Firm creation series

- GDP: Real Gross Domestic Product, Billions of Chained 2009 Dollars, Quarterly, Seasonally Adjusted Annual Rate (Fred series), divided by population.

- Consumption: Real Personal Consumption Expenditures: Nondurable Goods + Real Personal Consumption Expenditures: Services, Billions of Chained 2009 Dollars, Quarterly, Seasonally Adjusted Annual Rate (Fred series1 + series2 and before 1999, BEA NIPA Table 2.3.3), divided by population.

- Investment: Real Personal Consumption Expenditures: Durable Goods + Real Gross Private Domestic Investment, Billions of Chained 2009 Dollars, Quarterly, Seasonally Adjusted Annual Rate (Fred series1 + series2 and before 1999, BEA NIPA Table 2.3.3), divided by population.

- Inflation: GDP Implicit Price Deflator, Index 2009=100, Quarterly, Seasonally Adjusted (Fred series), logarithmic first difference. 
- InvestmentPrice: Gross Private Domestic Investment Implicit Price Deflator, Index 2009=100, Quarterly, Seasonally Adjusted (Fred series), divided by GDP Deflator.

- Hours: Nonfarm Business Sector: Hours of All Persons, Index 2009=100, Quarterly, Seasonally Adjusted (Fred series).

- Wage: Nonfarm Business Sector: Compensation Per Hour, Index 2009=100, Quarterly, Seasonally Adjusted (Fred series), divided by GDP Deflator.

- $\mathrm{R}$ for the short-term risk-free rates: Effective Federal Funds Rate, Percent, Quarterly, Not Seasonally Adjusted (Fred series).

- Credit: Nonfinancial Noncorporate Business; Credit Market Instruments; Liability + Nonfinancial Corporate Business; Credit Market Instruments; Liability, Level, Billions of Dollars, Quarterly, Not Seasonally Adjusted (Fred series1 + series2), divided by GDP Deflator, divided by population.

- CreditSpread: Moody's Seasoned Baa Corporate Bond Yield, Percent, Quarterly, Not Seasonally Adjusted (Fred series), less 10-year Government Bond Yield.

- NetWorth for entrepreneurial net worth: Wilshire 5,000 Total Market Index, Quarterly, Not Seasonally Adjusted (Fred series), divided by GDP Deflator.

- Population: Working Age Population: Aged 15-64: All Persons for the United States, Persons, Quarterly, Seasonally Adjusted (Fred series). 


\section{Additional Figures and Tables}

Firm destruction
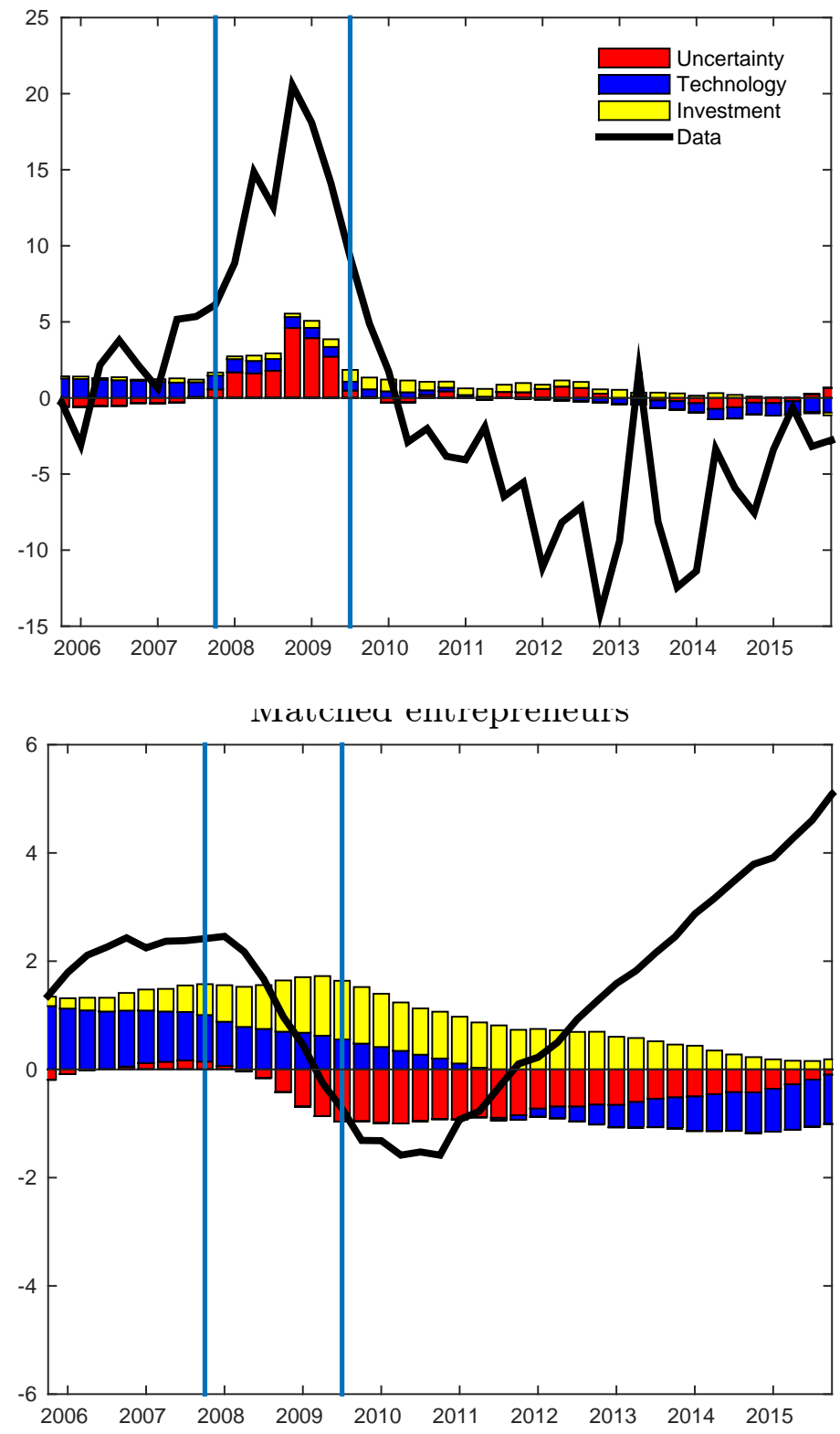

Figure 2.2 - Historical data and historical contribution of selected shocks to firm destruction and number of active firms ("matched entrepreneurs") (in log, percentage deviation), during the Great Recession. "Uncertainty" stands for the risk shock (both anticipated and unanticipated components); "Technology" stands for the technology shock (both persistent and temporary components); "Investment" stands for the investment efficiency shock. The two series of firm destruction and active firm (matched entrepreneurs) are not directly included in the estimation. 


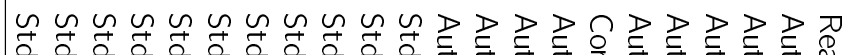

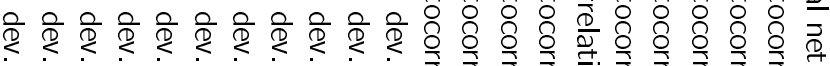

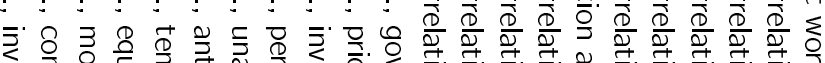

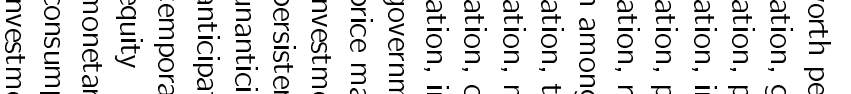

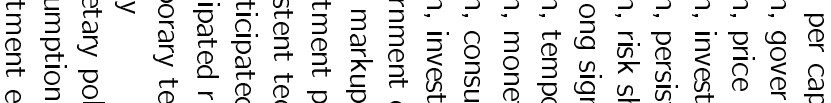

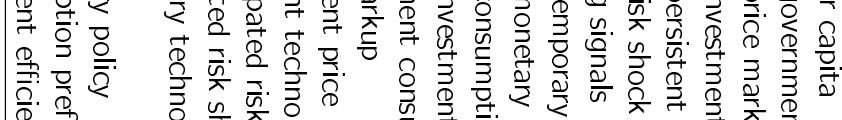

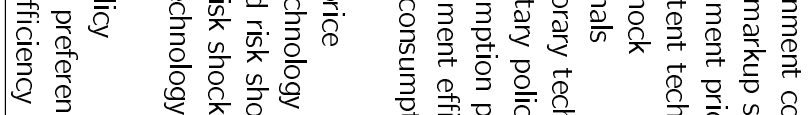

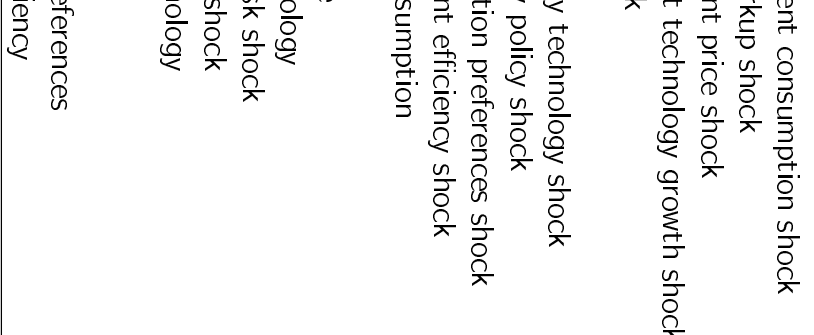

$$
\text { (1) }
$$

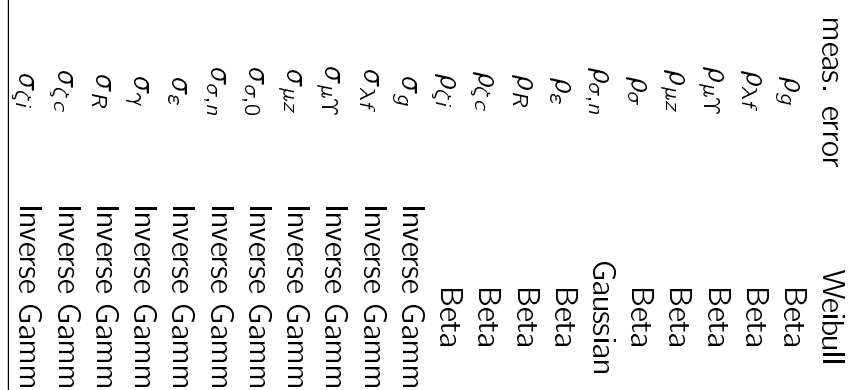

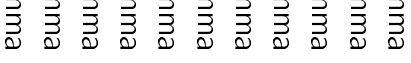

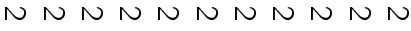

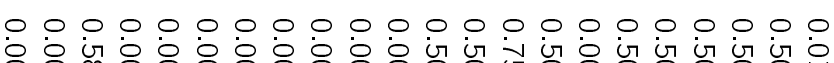

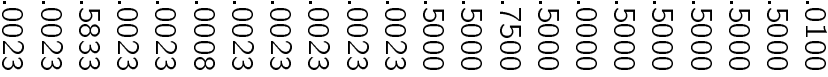

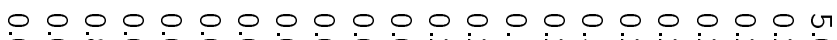

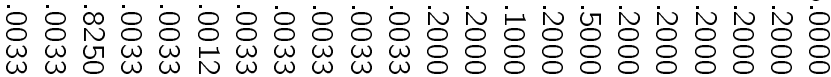

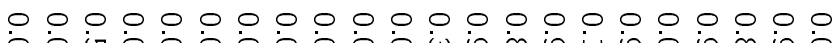

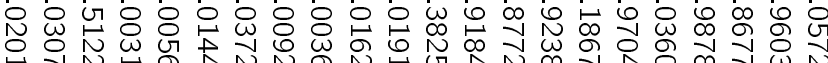

$\therefore \circ \circ \circ 0,0000000001000000$

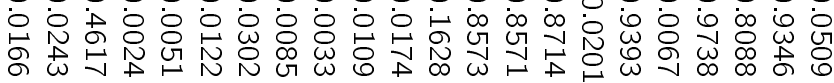

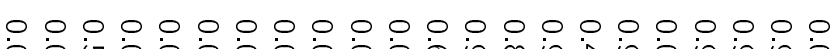

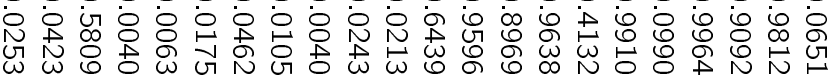

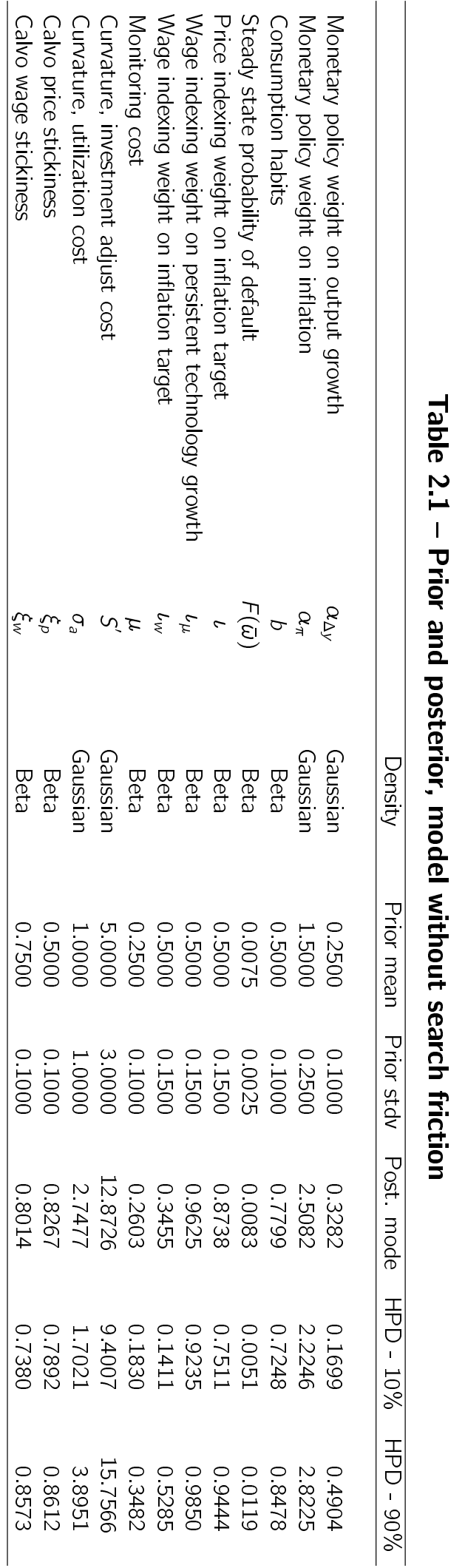




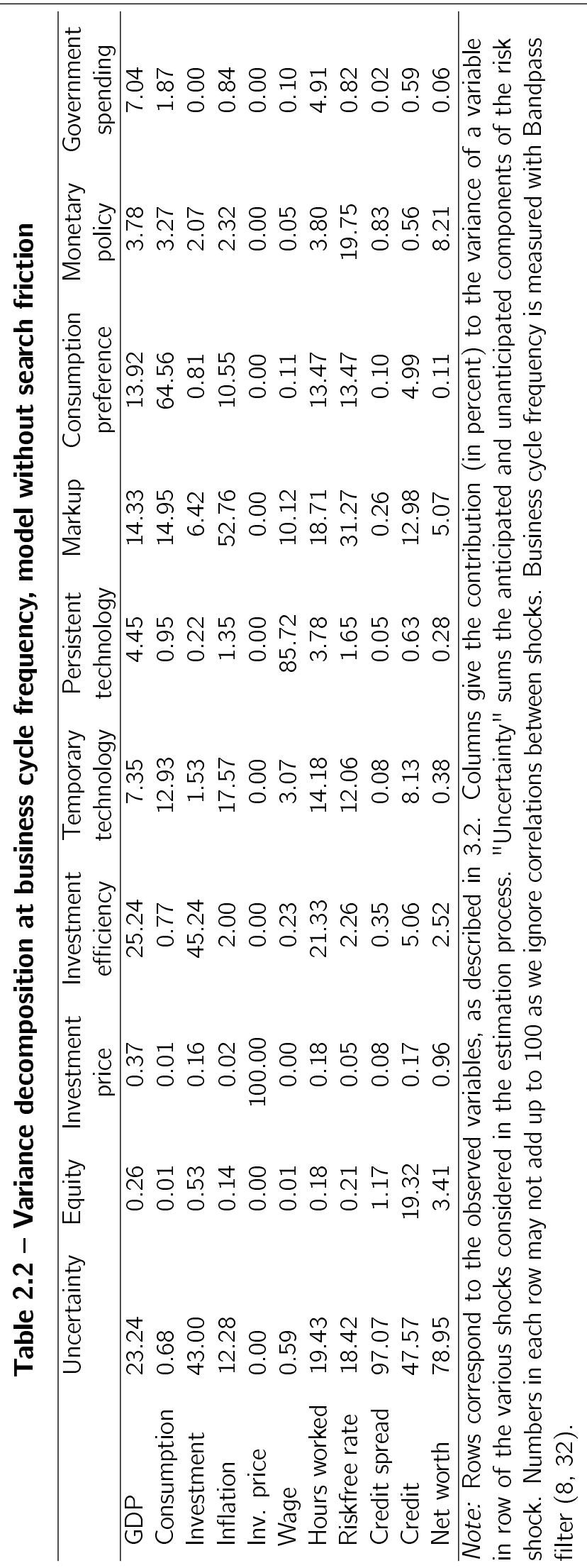




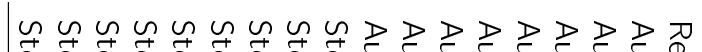

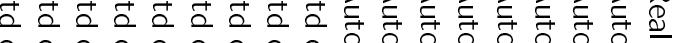

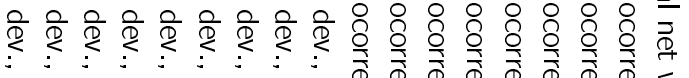

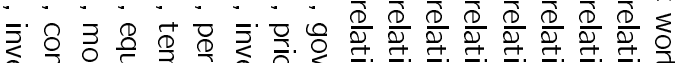

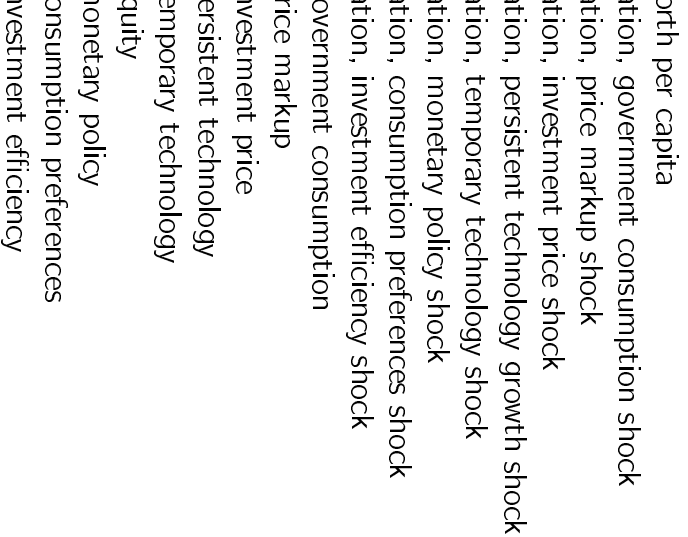
을 국 रे $\overline{\bar{\lambda}} \overline{\bar{d}} \overline{\bar{\lambda}} \overline{\bar{\lambda}} \overline{\bar{\lambda}} \overline{\bar{\lambda}} \overline{\bar{\lambda}} \overline{\bar{\lambda}} \overline{\bar{\lambda}}$

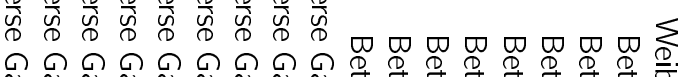

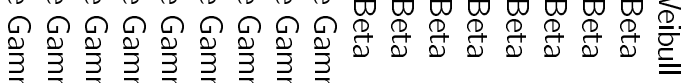

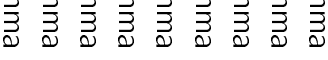

NNNNNNNNN

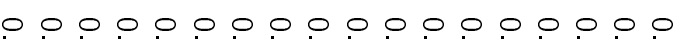

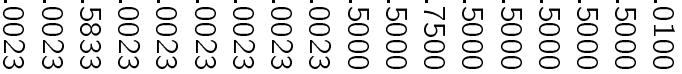

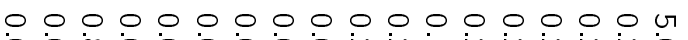

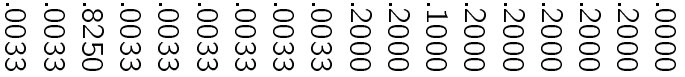

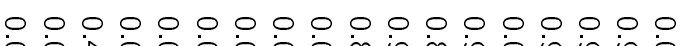

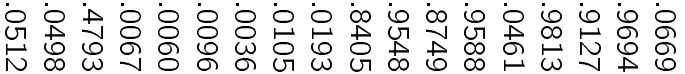

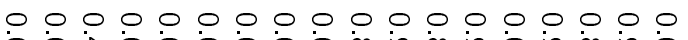

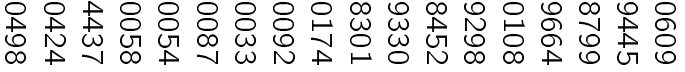

$\bigcirc \bigcirc \circ \bigcirc \bigcirc \bigcirc \bigcirc \bigcirc \bigcirc \bigcirc \bigcirc \bigcirc \bigcirc \bigcirc \bigcirc \bigcirc \bigcirc$

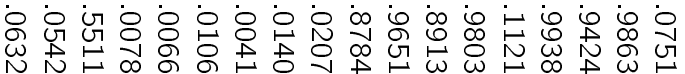

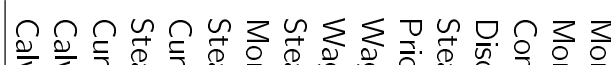

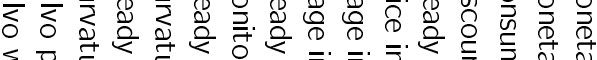

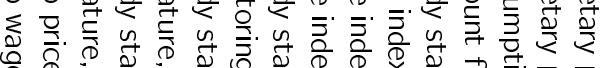

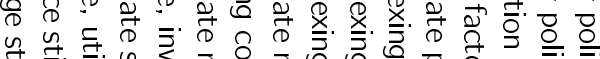

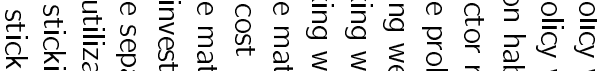

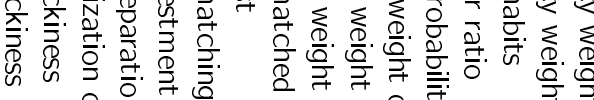
$\delta$ 웅

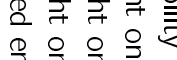

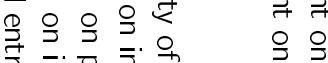

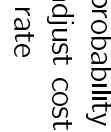

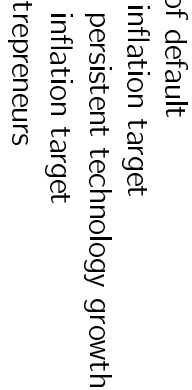

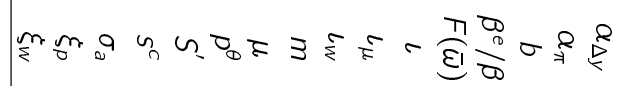

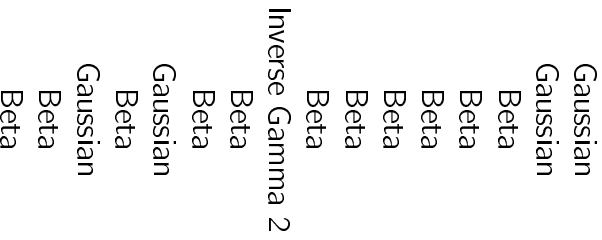

$\circ \circ \mapsto \circ \mu \circ \bigcirc \vdash \bigcirc \bigcirc \bigcirc \bigcirc \bigcirc \bigcirc \vdash \circ$

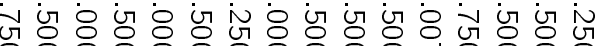

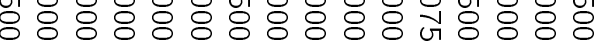

$00,0 \omega, 0000000000$

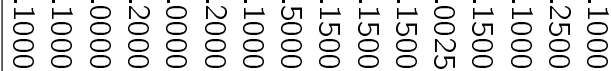

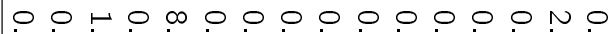

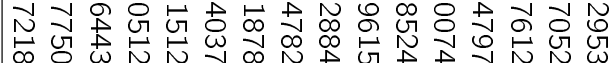

$0.0 .000000000000 n$

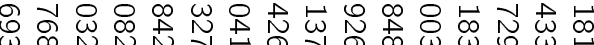

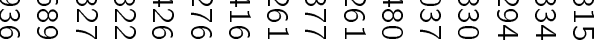

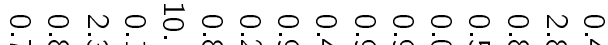

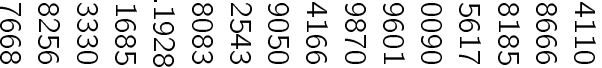

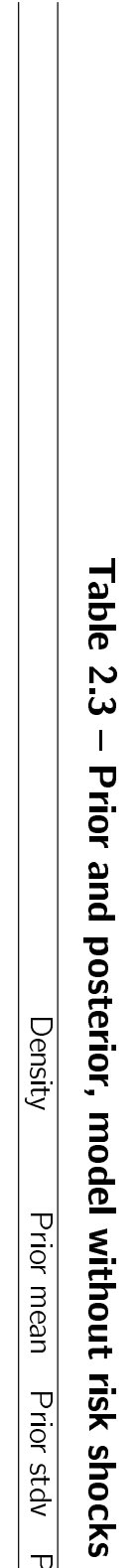




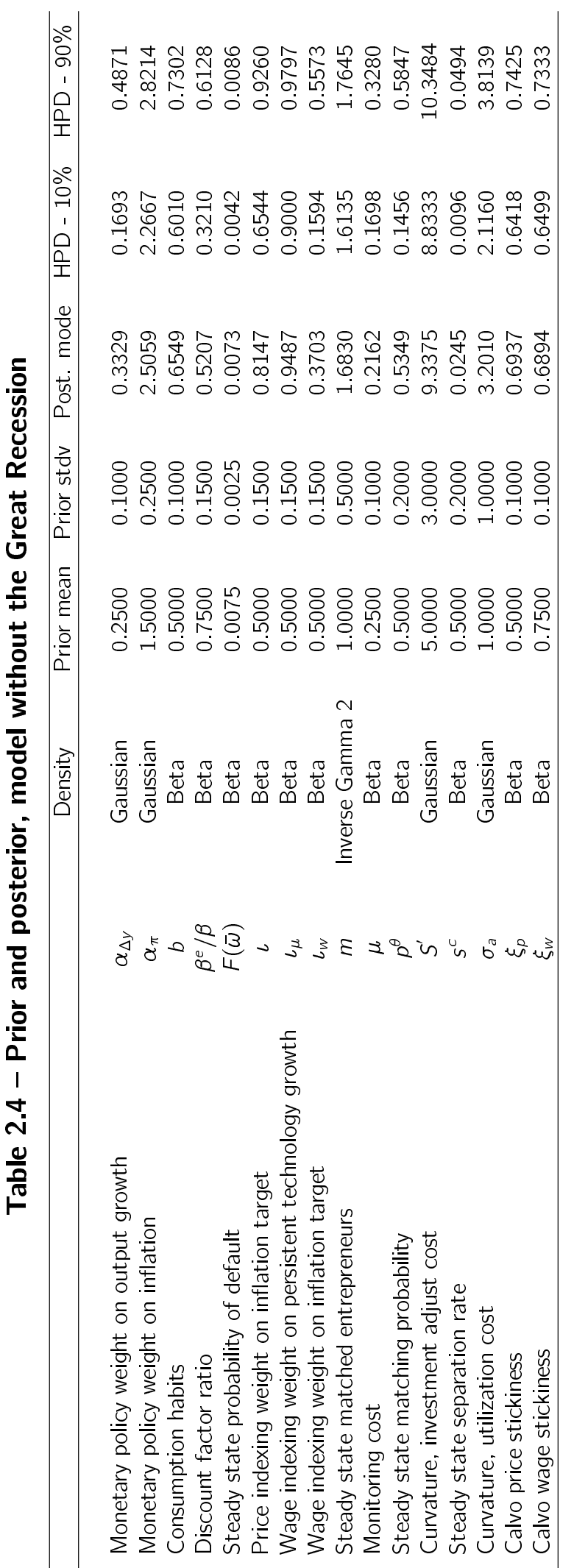

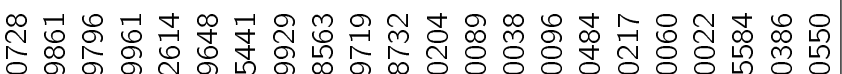
o. : :

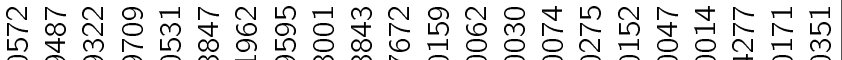
品

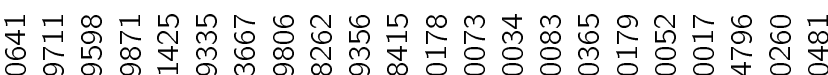

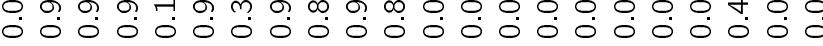

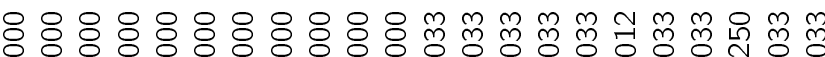

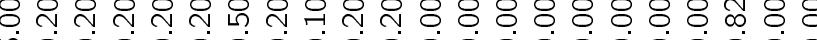
ঃ o o o o o ó ó.

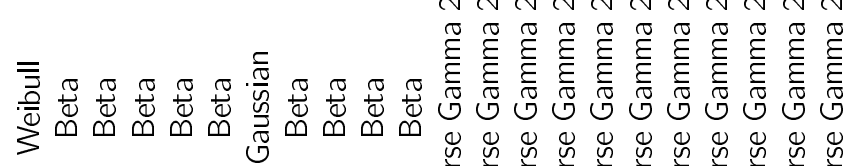

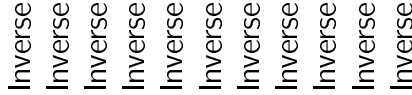
๖े

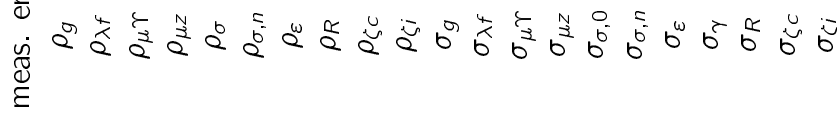

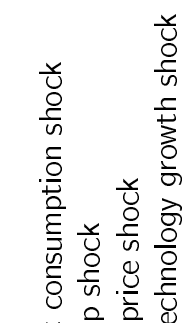

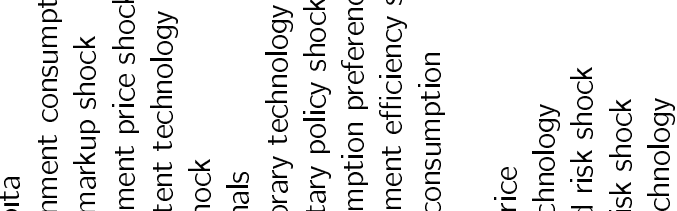

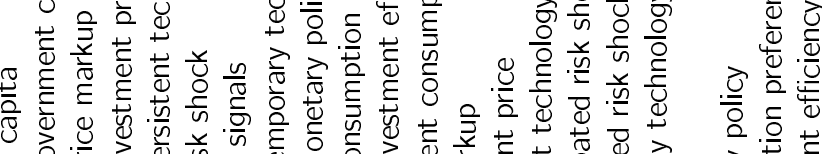

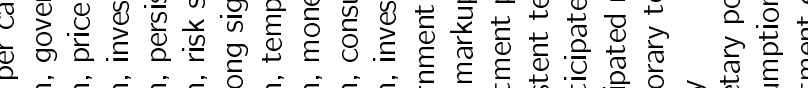

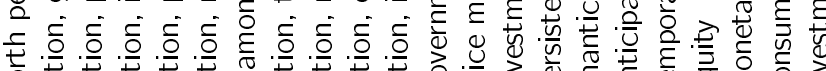

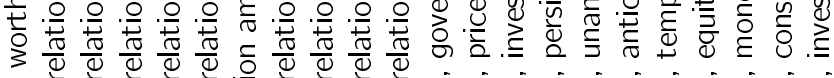

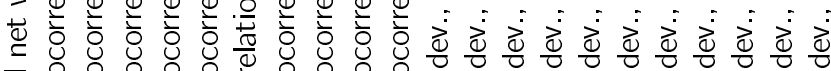

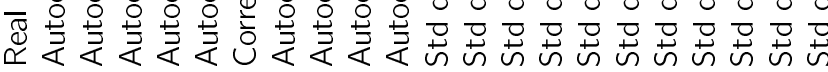




\section{Full model}

\section{A. Monopolistic producers}

\section{A.1. Cost minimization}

Monopolistic producers, indexed by $j$, demand capital and labor in order to maximize their cost of production subject to the demand function for their good, i.e

$$
\min P_{t} \tilde{r}_{t}^{k} u_{t} \bar{K}_{j, t}+W_{t} l_{j, t}
$$

$$
\text { s.t } \quad Y_{j, t}=\varepsilon_{t}\left(u_{t} \bar{K}_{j, t}\right)^{\alpha}\left(z_{t} l_{j, t}\right)^{1-\alpha}-\varphi z_{t}^{*}
$$

with $u$ the utilization rate of capital (determined further below), $\varphi$ a fixed cost of production, $z_{t}^{*}$ and $\varepsilon_{t}$ persistent and temporary technology shocks. The first-order conditions are

$$
\left(K_{j, t}:\right) \quad P_{t} \tilde{r}_{t}^{k}=\Lambda_{t}^{p} \alpha \varepsilon_{t}\left(\frac{z_{t} l_{j, t}}{u_{t} \bar{K}_{j, t}}\right)^{1-\alpha}
$$

and

$$
\left(I_{j, t}:\right) \quad W_{t}=\Lambda_{t}^{p}(1-\alpha) \varepsilon_{t} z_{t}\left(\frac{z_{t} l_{j, t}}{u_{t} \bar{K}_{j, t}}\right)^{-\alpha}
$$

where $\Lambda_{t}^{p}$ denotes the Lagrange multiplier associated with (3.1), interpreted as nominal marginal costs. Since all firms choose identical capital-labor ratios, we have

$$
\tilde{r}_{t}^{k}=\lambda_{t}^{p} \alpha \varepsilon_{t}\left(\frac{z_{t} l_{t}}{u_{t} \bar{K}_{t}}\right)^{1-\alpha}
$$

and

$$
W_{t}=\lambda_{t}^{p} P_{t}(1-\alpha) \varepsilon_{t} z_{t}\left(\frac{z_{t} l_{t}}{u_{t} \bar{K}_{t}}\right)^{-\alpha}
$$


where $\lambda_{t}^{p} \equiv \frac{\Lambda_{t}^{p}}{P_{t}}$ are real marginal costs. Combining (3.2) and (3.3) in order to eliminate the capital-labor ratio, we get real marginal costs as

$$
\lambda_{t}^{p}=\frac{1}{\varepsilon_{t}}\left(\frac{\tilde{r}_{t}^{k}}{\alpha}\right)^{\alpha}\left(\frac{W_{t}}{z_{t} P_{t}(1-\alpha)}\right)^{1-\alpha}
$$

\section{A.2. Profit maximization}

The good $j$ producer faces a Dixit-Stiglitz demand as

$$
Y_{j, t}=Y_{t}\left(\frac{P_{j, t}}{P_{t}}\right)^{-\frac{\lambda_{f, t}}{\lambda_{f, t}}}
$$

where $\lambda_{f, t}$, the elasticity of substitution among intermediate goods, is subject to a "price markup shock'. Therefore, its nominal profit flows can be written as

$$
E_{t}\left\{\sum_{k=0}^{\infty}\left(\beta \xi_{p}\right)^{k} \zeta_{c, t+k} \Lambda_{t+k} P_{t+k} Y_{t+k}\left[\left(\frac{P_{j, t}}{P_{t}}\right)^{1-\frac{\lambda_{f, t}}{\lambda_{f, t}-1}}-\lambda_{t+k}^{p}\left(\frac{P_{j, t}}{P_{t}}\right)^{-\frac{\lambda_{f, t}}{\lambda_{f, t}-1}}\right]\right\}
$$

where $\xi_{p}$ is the Calvo probability of not being able to change its price. Denoting $y_{z, t} \equiv Y_{t} / z_{t}^{*}$ and $\lambda_{z, t} \equiv \Lambda_{t} P_{t} z_{t}^{*}$, this can be rewritten as

$$
E_{t}\left\{\sum_{k=0}^{\infty}\left(\beta \xi_{p}\right)^{k} \zeta_{c, t+k} \lambda_{t+k} y_{t+k}\left[\left(\frac{P_{j, t}}{P_{t}}\right)^{1-\frac{\lambda_{f, t}}{\lambda_{f, t}-1}}-\lambda_{t+k}^{p}\left(\frac{P_{j, t}}{P_{t}}\right)^{-\frac{\lambda_{f, t}}{\lambda_{f, t}-1}}\right]\right\}
$$

Further, let us define the optimal relative price to be reset at time $t$ as

$$
\tilde{p}_{t} \equiv \frac{P_{j, t}}{P_{t}}
$$


such that we can also write

$$
\frac{P_{i, t+k}}{P_{t+k}}=\tilde{p}_{t} X_{t, k}
$$

where

$$
X_{t, k}=\left\{\begin{array}{l}
1 \text { if } k=0 \\
\frac{\tilde{\pi}_{t+1} \cdots \tilde{\pi}_{t+k}}{\pi_{t+1} \cdots \pi_{t+k}}, \quad \forall k>0, \quad \text { otherwise. }
\end{array}\right.
$$

Therefore, the good $j$ producer's objective function is

$$
\max _{\tilde{p}_{t}} E_{t}\left\{\sum_{k=0}^{\infty}\left(\beta \xi_{p}\right)^{k} \zeta_{c, t+k} \lambda_{t+k} y_{t+k}\left[\left(\tilde{p}_{t} X_{t, k}\right)^{1-\frac{\lambda_{f}}{\lambda_{f}-1}}-\lambda_{t+k}^{p}\left(\tilde{p}_{t} X_{t, k}\right)^{-\frac{\lambda_{f}}{\lambda_{f}-1}}\right]\right\}
$$

The first-order condition is

$$
E_{t}\left\{\sum_{k=0}^{\infty}\left(\beta \xi_{p}\right)^{k} \zeta_{c, t+k} \lambda_{z, t+k} y_{z, t+k}\left[\left(1-\frac{\lambda_{f}}{\lambda_{f}-1}\right)\left(\tilde{p}_{t} X_{t, k}\right)^{-\frac{\lambda_{f}}{\lambda_{f}-1}} X_{t, k}+\frac{\lambda_{f}}{\lambda_{f}-1} \lambda_{t+k}^{p}\left(\tilde{p}_{t} X_{t, k}\right)^{-\frac{\lambda_{f}}{\lambda_{f}-1}-1} X_{t, k}\right]\right\}=
$$

$$
\Leftrightarrow \quad \tilde{p}_{t}=\frac{E_{t}\left\{\sum_{k=0}^{\infty}\left(\beta \xi_{p}\right)^{k} \zeta_{c, t+k} \lambda_{z, t+k} y_{z, t+k}\left(X_{t, k}\right)^{\frac{\lambda_{f}}{1-\lambda_{f}}} \lambda_{f} \lambda_{t+k}^{p}\right\}}{E_{t}\left\{\sum_{k=0}^{\infty}\left(\beta \xi_{p}\right)^{k} \zeta_{c, t+k} \lambda_{z, t+k} y_{z, t+k}\left(X_{t, k}\right)^{\frac{\lambda_{f}}{1-\lambda_{f}}} X_{t, k}\right\}}
$$

This expression can be written in terms of auxiliary recursive variables as

$$
\tilde{p}_{t}=\frac{K_{p, t}}{F_{p, t}}
$$

with

$$
K_{p, t}=\zeta_{c, t} \lambda_{z, t} y_{z, t} \lambda_{f} \lambda_{t}^{p}+E_{t}\left[\beta \xi_{p}\left(\frac{\tilde{\pi}_{t+1}}{\pi_{t+1}}\right)^{\frac{\lambda_{f}}{1-\lambda_{f}}} K_{p, t+1}\right]
$$


and

$$
F_{p, t}=\zeta_{c, t} \lambda_{z, t} y_{z, t}+E_{t}\left[\beta \xi_{p}\left(\frac{\tilde{\pi}_{t+1}}{\pi_{t+1}}\right)^{\frac{1}{1-\lambda_{f}}} F_{p, t+1}\right]
$$

\section{A.3. Aggregate price index}

Given all intermediate good prices, the aggregate price index is

$$
P_{t}=\left(\int_{0}^{1} P_{j, t}^{\frac{1}{1-\lambda}} d j\right)^{1-\lambda_{f, t}}
$$

In terms of old and optimal price setters, it can be written as

$$
\begin{gathered}
P_{t}=\left[\int_{1-\xi_{p}}\left(\tilde{p}_{t} P_{t}\right)^{\frac{1}{1-\lambda_{f, t}}} d j+\int_{\xi_{p}}\left(P_{j, t-1} \tilde{\pi}_{t}\right)^{\frac{1}{1-\lambda_{f, t}}} d j\right]^{1-\lambda_{f, t}} \\
\Leftrightarrow \quad P_{t}=\left[\left(1-\xi_{p}\right)\left(\tilde{p}_{t} P_{t}\right)^{\frac{1}{1-\lambda_{f, t}}}+\xi_{p}\left(P_{t-1} \tilde{\pi}_{t}\right)^{\frac{1}{1-\lambda_{f, t}}}\right]^{1-\lambda_{f, t}}
\end{gathered}
$$

by the law of large numbers, and with the rule of thumb

$$
\tilde{\pi}_{t} \equiv\left(\pi^{\text {target }}\right)^{\iota_{p}}\left(\pi_{t-1}\right)^{1-\iota_{p}}
$$

where $\pi^{\text {target }}$ is the target inflation rate of the monetary authority.

Alternatively, define the aggregate price index as

$$
P_{t}^{*}=\left(\int_{0}^{1} P_{j, t}^{\frac{\lambda_{f, t}}{1-\lambda_{f, t}}} d j\right)^{\frac{1-\lambda_{f, t}}{\lambda_{f, t}}}
$$

Then, we can define the real auxiliary price index $p_{t}^{*}$ as 


$$
p_{t}^{*} \equiv \frac{P_{t}^{*}}{P_{t}}=\left[\int_{0}^{1}\left(\frac{P_{j, t}}{P_{t}}\right)^{\frac{\lambda_{f, t}}{1-\lambda_{f, t}}} d j\right]^{\frac{1-\lambda_{f, t}}{\lambda_{f, t}}}
$$

In terms of old and optimal price setters, it can be written as

$$
\begin{aligned}
p_{t}^{*}= & {\left[\int_{1-\xi_{p}}\left(\tilde{p}_{t}\right)^{\frac{\lambda_{f, t}}{1-\lambda_{f, t}}} d j+\int_{\xi_{p}}\left(\frac{P_{j, t-1} \tilde{\pi}_{t}}{P_{t-1} \pi_{t}}\right)^{\frac{\lambda_{f, t}}{1-\lambda_{f, t}}} d j\right]^{\frac{1-\lambda_{f, t}}{\lambda_{f, t}}} } \\
\Leftrightarrow & p_{t}^{*}=\left[\left(1-\xi_{p}\right)\left(\frac{K_{p, t}}{F_{p, t}}\right)^{\frac{\lambda_{f, t}}{1-\lambda_{f, t}}}+\xi_{p}\left(p_{t-1}^{*} \frac{\tilde{\pi}_{t}}{\pi_{t}}\right)^{\frac{\lambda_{f, t}}{1-\lambda_{f, t}}}\right]^{\frac{1-\lambda_{f, t}}{\lambda_{f, t}}}
\end{aligned}
$$

by the law of large numbers and using (3.5).

Finally, using (3.5), note that (3.8) can be rewritten as

$$
\begin{gathered}
P_{t}=\left(\left(1-\xi_{p}\right)\left(\frac{K_{p, t}}{F_{p, t}} P_{t}\right)^{\frac{1}{1-\lambda_{f}}}+\xi_{p}\left(\tilde{\pi}_{t} P_{t-1}\right)^{\frac{1}{1-\lambda_{f}}}\right)^{1-\lambda_{f}} \\
\Leftrightarrow \quad 1=\left(1-\xi_{p}\right)\left(\frac{K_{p, t}}{F_{p, t}}\right)^{\frac{1}{1-\lambda_{f}}}+\xi_{p}\left(\frac{\tilde{\pi}_{t}}{\pi_{t}}\right)^{\frac{1}{1-\lambda_{f}}} \\
\Leftrightarrow \quad\left(\frac{K_{p, t}}{F_{p, t}}\right)^{\frac{1}{1-\lambda_{f}}}=\frac{1-\xi_{p}\left(\frac{\tilde{\pi}_{t}}{\pi_{t}}\right)^{\frac{1}{1-\lambda_{f}}}}{\left(1-\xi_{p}\right)} \\
\Leftrightarrow \quad K_{p, t}=F_{p, t}\left(\frac{1-\xi_{p}\left(\frac{\tilde{\pi}_{t}}{\pi_{t}}\right)^{\frac{1}{1-\lambda_{f}}}}{\left(1-\xi_{p}\right)}\right)^{1-\lambda_{f}}
\end{gathered}
$$

which no longer incorporates $\tilde{p}_{t}$ itself. 


\section{A.4. Aggregate production function}

Integrating over individual goods, the aggregate quantity index is

$$
\begin{gathered}
Y_{t}^{*}=\int_{0}^{1} Y_{j, t} d j=\int_{0}^{1} Y_{t}\left(\frac{P_{t}}{P_{j, t}}\right)^{\frac{\lambda_{f, t}}{\lambda_{f, t}-1}} d j=Y_{t} P_{t}^{\frac{\lambda_{f, t}}{\lambda_{f, t}-1}} \int_{0}^{1} P_{j, t}^{\frac{\lambda_{f, t}}{1-\lambda_{f, t}}} d j=Y_{t} P_{t}^{\frac{\lambda_{f, t}}{\lambda_{f, t}}}\left(P_{t}^{*}\right)^{\frac{\lambda_{f, t}}{1-\lambda_{f, t}}} \\
=Y_{t}\left(p_{t}^{*}\right)^{\frac{\lambda_{f, t}}{1-\lambda_{f, t}}}
\end{gathered}
$$

Using the production function, we also have

$$
Y_{t}^{*}=\int_{0}^{1} Y_{j, t} d j=\int_{0}^{1}\left[\varepsilon_{t}\left(u_{t} \bar{K}_{j, t}\right)^{\alpha}\left(z_{t} l_{j, t}\right)^{1-\alpha}-\varphi z_{t}^{*}\right] d j=\varepsilon_{t}\left(u_{t} \bar{K}_{t}\right)^{\alpha}\left(z_{t} I_{t}\right)^{1-\alpha}-\varphi z_{t}^{*}
$$

since all firms choose identical input ratios and inputs are homogeneous. Combining both expressions, we get

$$
Y_{t}=\left(p_{t}^{*}\right)^{\frac{\lambda_{f, t}}{\lambda_{f, t}-1}}\left[\varepsilon_{t}\left(u_{t} \bar{K}_{t}\right)^{\alpha}\left(z_{t} l_{t}\right)^{1-\alpha}-\varphi z_{t}^{*}\right]
$$

\section{B. Households}

There is a unit mass of identical infinitely-lived households. They own the competitive producers of final goods, the monopolistic producers of intermediate goods, and the competitive financial intermediation sector. They derive utility from consumption and leisure. They provide differentiated labor services to the intermediate good firms. Households have two savings vehicles, raw capital and short-term bonds. Finally, they pay taxes to a public authority. 


\section{B.1. Consumption, bonds, and investment decisions}

A representative household maximizes the expected discounted sum of utilities given by

$$
\mathrm{E}_{0} \sum_{t=0}^{\infty} \beta^{t} \zeta_{c, t}\left\{\log \left(C_{t}-b C_{t-1}\right)-\psi_{L} \int_{0}^{1} \frac{h_{i, t}^{1+\sigma_{L}}}{1+\sigma_{L}} d i\right\}
$$

subject to the law of capital accumulation

$$
\bar{K}_{t+1}=(1-\delta) \bar{K}_{t}+\left[1-S\left(\zeta_{l, t} \frac{I_{t}}{I_{t-1}}\right)\right] I_{t}
$$

and the budget constraint

$R_{t} B_{t}+\left(1-\tau^{\prime}\right) \int_{0}^{1} W_{i, t} h_{i, t} d i+Q_{K, t} \bar{K}_{t+1}+\Pi_{t}=B_{t+1}+\left(1+\tau^{c}\right) P_{t} C_{t}+Q_{K, t}(1-\delta) \bar{K}_{t}+\frac{P_{t}}{\Upsilon^{t} \mu \mu_{\Upsilon, t}} I_{t}$ where $C$ stands for consumption, $P$ the price of consumption, $h$ hours worked, $K$ capital, $Q_{K}$ the price of capital, I investment, $B$ one-period bonds, $R$ the nominal interest rate on these bonds, $W$ the wage, $\beta$ the discount factor, $b$ the degree of habit formation, $\tau^{c}$ and $\tau^{\prime}$ are consumption and labor tax rates, $\zeta_{c}$ a consumption preference shock, $\zeta_{l}$ a shock on the marginal efficiency of investment in producing capital, and $S(x)$ an investment adjustment cost function of the form

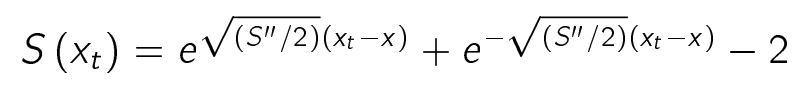

with $S^{\prime \prime}$ a curvature parameter and $x_{t} \equiv\left(\zeta_{l, t} \frac{I_{t}}{I_{t-1}}\right)$ with steady-state level $x$.

Replace $Q_{K, t}\left[K_{t}-(1-\delta) K_{t-1}\right]$ with $Q_{K, t}\left[1-S\left(\zeta_{l, t} I_{t} / I_{t-1}\right)\right] I_{t}$ from the capital accumulation into the budget constraint, denote $\wedge^{h}$ the Lagrange multiplier associated with the single constraint remaining in the household's problem, and derive the first-order conditions with respect to 
consumption, bonds, and investment, respectively as

$$
\begin{gathered}
\left(C_{t}:\right) \quad \frac{\zeta_{c, t}}{C_{t}-b C_{t-1}}-\beta E_{t}\left(\frac{b \zeta_{c, t+1}}{C_{t+1}-b C_{t}}\right)=\Lambda_{t}^{h} \zeta_{c, t} P_{t}\left(1+\tau^{c}\right) \\
\left(B_{t}:\right) \quad \Lambda_{t}^{h} \zeta_{c, t}=\beta E_{t}\left(\Lambda_{t+1}^{h} \zeta_{c, t+1} R_{t+1}\right) \\
\left(I_{t}:\right) \quad \Lambda_{t}^{h} \zeta_{c, t}\left[\frac{P_{t}}{\Upsilon^{t} \mu_{\Upsilon, t}}-Q_{K, t}\left(1-S_{t}-S_{t}^{\prime} \zeta_{I, t} \frac{I_{t}}{I_{t-1}}\right)\right] \\
=\beta E_{t}\left[\Lambda_{t+1}^{h} \zeta_{c, t+1} Q_{K, t+1} S_{t+1}^{\prime} \zeta_{I, t+1}\left(\frac{I_{t+1}}{I_{t}}\right)^{2}\right]
\end{gathered}
$$

Furthermore, from (3.17), the stochastic discount factor is

$$
\beta_{t, t+1}^{\star} \equiv \beta \frac{\Lambda_{t+1}^{h}}{\Lambda_{t}^{h}} \frac{\zeta_{c, t+1}}{\zeta_{c, t}}=\frac{1}{R_{t+1}}
$$

\section{B.2. Labor decisions and wages}

- The labor contractor problem

Households' differentiated labor services are aggregated by a "labor contractor" into homogeneous labor supply as

$$
I_{t}=\left[\int_{0}^{1}\left(h_{t, i}\right)^{\frac{1}{\lambda_{w}}} d i\right]^{\lambda_{w}}
$$

with $\lambda_{w} \geq 1$ the elasticity of substitution of the $i$ labor types. This homogeneous labor is sold to monoplistic producers at wage $W_{t}$ whereas each worker's type $i$ is paid a wage $W_{t, i}$. Therefore, 
the contractor choses the quantity of each labor $i$ type, $h_{i, t}$, such that

$$
\max _{h_{i, t}} W_{t} I_{t}-\int_{0}^{1} W_{t, i} h_{t, i} d i
$$

The first-order condition gives the demand for labor type $i$ as

$$
h_{t, i}=I_{t}\left(\frac{W_{t}}{W_{t, i}}\right)^{\frac{\lambda_{w}}{\lambda_{w}-1}}
$$

- The aggregate wage index and hours

For each labor type, workers are represented by a monopoly union setting up the wage of their type $W_{t, i}$, subject to a Calvo-type friction. At each date $t$, a fraction $\xi_{w}$ cannot reoptimize their wage but update it as

$$
W_{t, i}=\left(\mu_{z, t}^{*}\right)^{\iota_{\mu}}\left(\mu_{z}^{*}\right)^{1-\iota_{\mu}} \tilde{\pi}_{w, t} W_{i, t-1}
$$

with

$$
\tilde{\pi}_{w, t}=\left(\pi_{t}^{\text {target }}\right)^{\iota_{w}}\left(\pi_{t-1}\right)^{1-\iota_{w}}
$$

while the $1-\xi_{w}$ part is able to chose an optimal wage level $\tilde{W}_{t}$, to be determined further below. Therefore, the aggregate wage index is

$$
\begin{gathered}
W_{t}=\left[\int_{0}^{1}\left(W_{t, i}\right)^{\frac{1}{1-\lambda_{w}}} d i\right]^{1-\lambda_{w}} \\
\Leftrightarrow W_{t}=\left\{\left(1-\xi_{w}\right)\left(\tilde{W}_{t}\right)^{\frac{1}{1-\lambda_{w}}}+\xi_{w}\left[\left(\mu_{z, t}^{*}\right)^{\iota_{\mu}}\left(\mu_{z}^{*}\right)^{1-\iota_{\mu}} \tilde{\pi}_{w, t} W_{t-1}\right]^{\frac{1}{1-\lambda_{w}}}\right\}^{1-\lambda_{w}}
\end{gathered}
$$


Denoting $\tilde{W}_{t} \equiv \tilde{W}_{t} / W_{t}$, this can be reexpressed as

$$
\tilde{W}_{t}=\left\{\frac{1-\xi_{w}\left[\frac{\tilde{\pi}_{w, t}}{\pi_{w, t}}\left(\mu_{z, t}^{*}\right)^{\iota_{\mu}}\left(\mu_{z}^{*}\right)^{1-\iota_{\mu}}\right]^{\frac{1}{1-\lambda_{w}}}}{1-\xi_{w}}\right\}^{1-\lambda_{w}}
$$

with

$$
\pi_{w, t} \equiv \frac{W_{t}}{W_{t-1}}
$$

the growth rate of the nominal wage.

Alternatively, we can write the aggregate wage index as

$$
\begin{gathered}
W_{t}^{*}=\left[\int_{0}^{1}\left(W_{t, i}\right)^{\frac{\lambda_{w}}{1-\lambda_{w}}} d i\right]^{\frac{1-\lambda_{w}}{\lambda_{w}}} \\
=\left\{\left(1-\xi_{w}\right)\left(\tilde{W}_{t}\right)^{\frac{\lambda_{w}}{1-\lambda_{w}}}+\xi_{w}\left[\left(\mu_{z, t}^{*}\right)^{\iota_{\mu}}\left(\mu_{z}^{*}\right)^{1-\iota_{\mu}} \tilde{\pi}_{w, t} W_{t-1}\right]^{\frac{\lambda_{w}}{1-\lambda_{w}}}\right\}^{\frac{1-\lambda_{w}}{\lambda_{w}}}
\end{gathered}
$$

Denoting $W_{t}^{*} \equiv W_{t}^{*} / W_{t}$, we have

$$
w_{t}^{*}=\left\{\left(1-\xi_{w}\right)\left(\tilde{w}_{t}\right)^{\frac{\lambda_{w}}{1-\lambda_{w}}}+\xi_{w}\left[\left(\mu_{z, t}^{*}\right)^{\iota_{\mu}}\left(\mu_{z}^{*}\right)^{1-\iota_{\mu}} \frac{\tilde{\pi}_{w, t}}{\pi_{w, t}} w_{t-1}^{*}\right]^{\frac{\lambda_{w}}{1-\lambda_{w}}}\right\}^{\frac{1-\lambda_{w}}{\lambda_{w}}}
$$

Substituting in (B.2), we can rewrite it as

$$
w_{t}^{*}=\left[\left(1-\xi_{w}\right)\left(\frac{1-\xi_{w}\left(\frac{\tilde{\pi}_{w, t}}{\pi_{w, t}}\left(\mu_{z^{*}}\right)^{1-\iota_{\mu}}\left(\mu_{z_{t}^{*}}\right)^{\iota_{\mu}}\right)^{\frac{1}{1-\lambda_{w}}}}{1-\xi_{w}}\right)^{\lambda_{w}}+\xi_{w}\left(\frac{\tilde{\pi}_{w, t}\left(\mu_{z^{*}, t}\right)^{\iota_{\mu}}\left(\mu_{z^{*}}\right)^{1-\iota_{\mu}}}{\pi_{w, t}} w_{t-1}^{*}\right)^{\frac{\lambda_{w}}{1-\lambda_{w}}}\right]^{\frac{1-\lambda_{w}}{\lambda_{w}}}
$$


Aggregating over hours and using the same notations, we have

$$
\begin{gathered}
h_{t}=\int_{0}^{1} h_{i, t} d i=I_{t} W_{t}^{\frac{\lambda_{w}}{\lambda_{W}-1}} \int_{0}^{1}\left(W_{t, i}\right)^{\frac{\lambda_{w}}{1-\lambda_{w}}} d i=I_{t} W_{t}^{\frac{\lambda_{W}}{\lambda_{W}-1}}\left(W_{t}^{*}\right)^{\frac{\lambda_{w}}{1-\lambda_{w}}} \\
\Leftrightarrow \quad h_{t}=I_{t}\left(W_{t}^{*}\right)^{\frac{\lambda_{w}}{1-\lambda_{w}}}
\end{gathered}
$$

- The intertemporal wage optimization

Households maximize their labor own labor type $i$ supply subject to the corresponding wage. Considering again their maximization problem, now with the Calvo signal, gives a Lagrangian as

$$
\mathcal{L}=E_{t}\left\{\sum_{k=0}^{\infty}\left(\beta \xi_{w}\right)^{k} \zeta_{c, t+k}\left(\Lambda_{t+k}^{h}\left(1-\tau_{L}\right) \int_{0}^{1} W_{i, t+k} h_{i, t+k} d i-\psi_{L} \int_{0}^{1} \frac{\left(h_{i, t+k}\right)^{1+\sigma_{L}}}{1+\sigma_{L}} d i\right)\right\}
$$

From previous results, we have $h_{i, t}=I_{t}\left(W_{t}\right)^{\frac{\lambda w}{\lambda_{w}-1}}\left(W_{i, t}\right)^{\frac{\lambda w}{1-\lambda_{w}}}$ and $W_{i, t} h_{i, t}=I_{t}\left(W_{t}\right)^{\frac{\lambda_{w}}{\lambda_{W}-1}}\left(W_{i, t}\right)^{\frac{\lambda w}{1-\lambda_{w}}+1}$ which can be substituted in as

$$
\begin{array}{r}
\mathcal{L}=E_{t}\left\{\sum _ { k = 0 } ^ { \infty } ( \beta \xi _ { w } ) ^ { k } \zeta _ { c , t + k } \left[\Lambda_{t+k} W_{t+k}\left(1-\tau_{L}\right) I_{t+k} \int_{0}^{1}\left(W_{t+k}\right)^{\frac{\lambda_{w}}{\lambda_{w}-1}-1}\left(W_{i, t+k}\right)^{1-\frac{\lambda_{w}}{\lambda_{w}-1}} d i\right.\right. \\
\left.\left.-\psi_{L} \frac{\left(I_{t+k}\right)^{1+\sigma_{L}}}{1+\sigma_{L}} \int_{0}^{1}\left(\frac{W_{t+k}}{W_{i, t+k}}\right)^{\frac{\lambda_{w}}{\lambda_{W}-1}\left(1+\sigma_{L}\right)} d i\right]\right\}
\end{array}
$$

which can be simplified, and using the $w_{t}$ and $\tilde{w}_{t}$ notations, rewritten as

$$
\begin{array}{r}
\mathcal{L}=E_{t}\left\{\sum _ { k = 0 } ^ { \infty } ( \beta \xi _ { w } ) ^ { k } \zeta _ { c , t + k } \left[\lambda_{z, t+k} W_{t+k}\left(1-\tau_{L}\right) I_{t+k}\left(\tilde{W}_{t} X_{t, k}\right)^{1-\frac{\lambda_{w}}{\lambda_{w}-1}}\right.\right. \\
\left.\left.-\psi_{L} \frac{\left(I_{t+k}\right)^{1+\sigma_{L}}}{1+\sigma_{L}}\left(\tilde{W}_{t} X_{t, k}\right)^{-\frac{\lambda_{w}}{\lambda_{w}-1}}\left(1+\sigma_{L}\right)\right]\right\}
\end{array}
$$


with

$$
X_{t, k}=\frac{\tilde{\pi}_{w, t+k}\left(\mu_{z, t+k}^{*}\right)^{\iota_{\mu}}\left(\mu_{z}^{*}\right)^{1-\iota_{\mu}} \cdots \tilde{\pi}_{w, t+1}\left(\mu_{z, t+1}^{*}\right)^{\iota_{\mu}}\left(\mu_{z}^{*}\right)^{1-\iota_{\mu}}}{\pi_{w, t+k} \cdots \pi_{w, t+1}}
$$

The first-order condition with respect to $\tilde{w}_{t}$ is

$$
\begin{array}{r}
E_{t}\left\{\sum_{k=0}^{\infty}\left(\beta \xi_{w}\right)^{k} \zeta_{c, t+k} \lambda_{z, t+k} W_{t+k}\left(1-\tau_{L}\right) I_{t+k}\left(1-\frac{\lambda_{w}}{\lambda_{w}-1}\right)\left(\tilde{w}_{t} X_{t, k}\right)^{-\frac{\lambda_{w}}{\lambda_{w}-1}} X_{t, k}\right\} \\
=E_{t}\left\{\sum_{k=0}^{\infty}\left(\beta \xi_{w}\right)^{k} \zeta_{c, t+k} \psi_{L} \frac{\left(I_{t+k}\right)^{1+\sigma_{L}}}{1+\sigma_{L}}\left[-\frac{\lambda_{w}}{\lambda_{w}-1}\left(1+\sigma_{L}\right)\right]\left(\tilde{w}_{t} X_{t, k}\right)^{-\frac{\lambda_{w}}{\lambda_{w}-1}\left(1+\sigma_{L}\right)-1} X_{t, k}\right\}
\end{array}
$$

which can be simplified as

$$
\begin{gathered}
E_{t}\left\{\sum_{k=0}^{\infty}\left(\beta \xi_{w}\right)^{k} \zeta_{c, t+k} \lambda_{z, t+k} \frac{1-\tau_{L}}{\lambda_{w}} \frac{W_{t+k}}{W_{t}} l_{t+k}\left(X_{t, k}\right)^{1-\frac{\lambda_{w}}{\lambda_{w}-1}}\right\} \\
=\frac{\psi_{L}}{w_{t}}\left(\tilde{W}_{t}\right)^{-\frac{\lambda_{w}}{\lambda_{w}-1} \sigma_{L}-1} E_{t}\left\{\sum_{k=0}^{\infty}\left(\beta \xi_{w}\right)^{k} \zeta_{c, t+k}\left(I_{t+k}\right)^{1+\sigma_{L}}\left(X_{t, k}\right)^{\frac{\lambda w}{1-\lambda_{w}}\left(1+\sigma_{L}\right)}\right\} \\
\Leftrightarrow \quad F_{w, t}=\frac{\psi_{L}}{W_{t}}\left(\tilde{W}_{t}\right)^{-\frac{\lambda_{w}}{\lambda_{w}-1} \sigma_{L}-1} K_{w, t}
\end{gathered}
$$

with

$$
F_{w, t}=\zeta_{c, t} \lambda_{z, t} \frac{\left(1-\tau_{L}\right)}{\lambda_{w}} I_{t}+E_{t}\left\{\beta \xi_{w} \zeta_{c, t+1} \lambda_{z, t+1} \frac{\left(1-\tau_{L}\right)}{\lambda_{w}} \frac{W_{t+1}}{w_{t}} I_{t+k 1}\left(\frac{\tilde{\pi}_{w, t+1}\left(\mu_{z, t+1}^{*}\right)^{\iota_{\mu}}\left(\mu_{z}^{*}\right)^{1-\iota_{\mu}}}{\pi_{w, t+1}}\right)^{\frac{1}{1-\lambda_{w}}}+\ldots\right\}
$$

and

$$
K_{w, t}=\zeta_{c, t}\left(I_{t}\right)^{1+\sigma_{L}}+E_{t}\left\{\beta \xi_{w} \zeta_{c, t+1}\left(I_{t+1}\right)^{1+\sigma_{L}}\left(\frac{\tilde{\pi}_{w, t+1}\left(\mu_{z, t+1}^{*}\right)^{\iota_{\mu}}\left(\mu_{z}^{*}\right)^{1-\iota_{\mu}}}{\pi_{w, t+1}}\right)^{\frac{\lambda_{w}}{1-\lambda_{w}}\left(1+\sigma_{L}\right)}+\ldots\right\}
$$


The last two expressions can be rewritten recursively as

$$
F_{w, t}=\zeta_{c, t} \lambda_{z, t} \frac{\left(1-\tau_{L}\right)}{\lambda_{w}} I_{t}+E_{t}\left[\beta \xi_{w}\left(\mu_{z}^{*}\right)^{\frac{1-\iota \mu}{1-\lambda_{w}}}\left(\mu_{z, t+1}^{*}\right)^{\frac{\iota \mu}{1-\lambda_{w}}}-1 \frac{\left(\tilde{\pi}_{w, t+1}\right)^{\frac{1}{1-\lambda_{w}}}}{\pi_{t+1}\left(\pi_{w, t+1}\right)^{\frac{\lambda w}{1-\lambda_{w}}}} F_{w, t+1}\right]
$$

and

$$
K_{w, t}=\zeta_{c, t}\left(I_{t}\right)^{1+\sigma_{L}}+E_{t}\left[\beta \xi_{w}\left(\frac{\tilde{\pi}_{w, t+1}\left(\mu_{z, t+1}^{*}\right)^{\iota_{\mu}}\left(\mu_{z}^{*}\right)^{1-\iota_{\mu}}}{\pi_{w, t+1}}\right)^{\frac{\lambda_{w}}{1-\lambda_{w}}\left(1+\sigma_{L}\right)} K_{w, t+1}\right]
$$

Finally, rearrange (3.24) as

$$
K_{w, t}=\frac{F_{w, t} W_{t}}{\psi_{L}}\left(\tilde{W}_{t}\right)^{1+\frac{\lambda_{w}}{\lambda_{w}-1} \sigma_{L}}
$$

and use (B.2) to obtain

$$
K_{w, t}=\frac{W_{t} F_{w, t}}{\psi_{L}}\left\{\frac{1-\xi_{w}\left[\frac{\tilde{\pi}_{w, t}}{\pi_{w, t}}\left(\mu_{z, t}^{*}\right)^{\iota_{\mu}}\left(\mu_{z}^{*}\right)^{1-\iota_{\mu}}\right]^{\frac{1}{1-\lambda_{w}}}}{1-\xi_{w}}\right\}^{1-\lambda_{w}\left(1+\sigma_{L}\right)}
$$

\section{Entrepreneurs}

\section{C.1. Return on capital and utilization rate of capital}

Once the idiosyncratic productivity shock is realized, entrepreneurs rent capital to the monopolistic producers. Before capital income tax, this yields

$$
u_{t} r_{t}^{k}-a\left(u_{t}\right)
$$


where $r_{t}^{k}$ is the rental rate per unit of utilized capital $u_{t}$ in period $t$ and where $a($.$) is a convex$ capital utilization cost function as

$$
a_{t}=\frac{r^{k}}{\sigma_{a}}\left[e^{\sigma_{a}\left(u_{t}-1\right)}-1\right]
$$

with $r^{k}$ the steady-state value of the rental rate and $\sigma_{a}$ a parameter. In steady-state, $u=1$, and therefore $a=0$ regardless the value of $\sigma_{a}$. The first-order condition with respect to the capital utilization rate $u_{t}$ is

$$
r_{t}^{k}=r^{k} e^{\sigma_{a}\left(u_{t}-1\right)}
$$

Across periods, the capital stock is then sold back to households and brings the difference between the market values of capital at date $t$ and $t-1$. Therefore, the return on capital can be defined as the after-tax net gain on capital rental plus the value of buying/selling capital across periods, i.e

$$
R_{t}^{k} \equiv \frac{\left(1-\tau^{k}\right)\left(u_{t} r_{t}^{k}-a\left(u_{t}\right)\right) \frac{P_{t}}{\Upsilon^{t}}+(1-\delta) Q_{\bar{k}, t}+\tau^{k} \delta Q_{\bar{k}, t-1}}{Q_{\bar{k}, t-1}}
$$

\section{C.2. Financial contract}

In the main text of the paper, we derived the three equations of the optimal financial contract, namely the participation constraint of bankers, (17), and the first-order conditions with respect to the borrowing amount, (18), and the default threshold, (19), respectively.

In addition, we use the following definitions,

$$
F_{t}=\operatorname{normcdf}\left(\frac{\log \left(\bar{\omega}_{t}\right)+\frac{\sigma_{\omega, t-1}^{2}}{2}}{\sigma_{\omega, t-1}}\right)
$$




$$
\begin{gathered}
G_{t}=\operatorname{normcdf}\left(\frac{\log \left(\bar{\omega}_{t}\right)+\frac{\sigma_{\omega, t-1}^{2}}{2}}{\sigma_{\omega, t-1}}-\sigma_{\omega, t-1}\right) \\
G_{t}^{\prime}=\frac{1}{\sqrt{2 \pi} \sigma_{\omega, t-1}} e^{\left.-\frac{1}{2}\left(\frac{\left.\log \left(\bar{\omega}_{t}\right)+\frac{\sigma_{\omega, t-1}^{2}}{\sigma_{\omega, t-1}}\right)^{2}}{2}\right) \sigma_{\omega, t-1}-2 \sigma_{\omega, t-1}\right)} \\
H_{t=n o r m c d f}\left(\left(\log \left(\bar{\omega}_{t}\right)+\frac{\sigma_{\omega, t-1}^{2}}{2}\right.\right. \\
\Gamma_{t}=\bar{\omega}_{t}\left(1-F_{t}\right)+G_{t} \\
\Gamma_{t}^{\prime}=1-F_{t}
\end{gathered}
$$

\section{C.3. Equations from the search friction}

From the main text, we have the definition of the entrepreneur's endogenous probability to

find a bank, (2), the definition of the credit market tightness, (3), the free-entry condition of entrepreneurs, (16), and the law of motion for the number of matched entrepreneurs, (26). Finally, the number of unmatched bankers is

$$
u_{t}^{b}=p o p^{b}-m_{t}
$$

where $p o p^{b}$ is a parameter for the total number of banks in the economy. 


\section{Market clearing}

At the aggregate level, net worth evolves as (22), the resource constraint is (23), montoring costs are (24), and the non-survival payoff is (25).

\section{E. Public authority}

It raises taxes, issue bonds, sets the nominal interest rate according to a Taylor-type rule, and consume some final good. The monetary policy rule is

$$
R_{t}-R=\rho_{p}\left(R_{t-1}-R\right)+\left(1-\rho_{p}\right)\left[\alpha_{\pi}\left(\pi_{t+1}-\pi_{t}^{*}\right)+\frac{\alpha_{\Delta y}}{4}\left(g_{y, t}-\mu_{z}^{*}\right)\right]+\frac{\varepsilon_{t}^{R}}{400}
$$

\section{F. Stationarization and final system}

Besides inflation $\pi_{t} \equiv P_{t} / P_{t-1}$, there are two other trends in this model, namely technical progress in the final good sector, $z_{t}^{*}$, and technical progress in the sector of physical capital accumulation, $\Upsilon^{t}$. Let us denote $\mu_{z^{*}, t} \equiv z_{t}^{*} / z_{t-1}^{*}$ the output productivity growth rate, and re-define the variables in real stationarized terms as follows:

- $y_{t} \equiv Y_{t} / z_{t}^{*}, c_{t} \equiv C_{t} / z_{t}^{*}, i_{z, t} \equiv I_{t} /\left(z_{t}^{*} \Upsilon^{t}\right)$, and $g_{t} \equiv G_{t} / z_{t}^{*}$ for (Real) output, consumption, investment, and public expenditures, respectively;

- $\lambda_{z, t} \equiv \Lambda_{t}^{h} z_{t}^{*} P_{t}$ for the marginal utility of consumption;

- $\bar{k}_{t+1} \equiv \bar{K}_{t+1} /\left(z_{t}^{*} \Upsilon^{t}\right), \bar{b}_{t+1} \equiv \bar{B}_{t+1} /\left(z_{t}^{*} P_{t}\right)$, and $\bar{n}_{t+1} \equiv \bar{N}_{t+1} /\left(z_{t}^{*} P_{t}\right)$, for aggregate capital, bonds, and entrepreneurial net worth, respectively;

- $q_{t} \equiv Q_{K, t} \Upsilon^{t} / P_{t}$ the price of capital, such that $q_{t} \bar{k}_{t+1} \equiv Q_{K, t} \bar{K}_{t+1} /\left(P_{t} z_{t}^{*}\right)$ are stationarized capital purchases;

- $w_{t} \equiv W_{t} /\left(z_{t}^{*} P_{t}\right)$ and $r_{t}^{k} \equiv \tilde{r}_{t}^{k} \Upsilon^{t}$ for the wage and rental rate of capital, respectively; 
- $z_{t} \equiv z_{t}^{*} \Upsilon^{-\frac{\alpha t}{1-\alpha}}$ for the trend of the fixed production cost;

- $\bar{c}_{t}^{e} \equiv \bar{C}_{t}^{e} / z_{t}^{*}$ for the non-survival real consumption payoff;

- $\bar{d}_{t}^{M} \equiv \bar{D}_{t}^{M} / z_{t}^{*}$ for real monitoring costs;

- $w^{e} \equiv W_{t}^{e} /\left(z_{t}^{*} P_{t}\right)$ for the net transfer from households to each matched entrepreneur, set as a fixed parameter (see Table 1);

- $d^{S} \equiv D_{t}^{S} /\left(z_{t}^{*} P_{t}\right)$ for individual periodic search cost (free entry condition), with value deducted from other estimated parameters.

This gives the following stationarized equilibrium system: (3.14) becomes

$$
\bar{k}_{t+1}=(1-\delta) \frac{1}{\mu_{z, t}^{*}} \bar{k}_{t}+\left[1-S\left(\frac{\zeta_{i, t} i_{t} \mu_{z, t}^{*} \Upsilon}{i_{t-1}}\right)\right] i_{t}
$$

(3.15) becomes

$$
S\left(x_{t}\right)=e^{\sqrt{\left(S^{\prime \prime} / 2\right)}\left(\zeta_{i, t} \mu_{z, t}^{*} \Upsilon^{\frac{i_{t}}{t_{t}-1}-\mu_{z}^{*} \Upsilon} \Upsilon\right.}+e^{-\sqrt{\left(S^{\prime \prime} / 2\right)}\left(\zeta_{i, t} \mu_{z, t}^{*} \Upsilon \frac{i_{t}}{t_{t}-1}-\mu_{z}^{*} \Upsilon\right)}-2
$$

with first-order derivative

$$
S^{\prime}\left(x_{t}\right)=\sqrt{\left(S^{\prime \prime} / 2\right)}\left(e^{\sqrt{\left(S^{\prime \prime} / 2\right)}\left(\zeta_{i, t} \mu_{z, t}^{*} \Upsilon \frac{i_{t}}{i_{t-1}}-\mu_{z}^{*} \Upsilon\right)}+e^{-\sqrt{\left(S^{\prime \prime} / 2\right)}\left(\zeta_{i, t} \mu_{z, t}^{*} \Upsilon \Gamma_{i t}-\mu_{t-1}^{*} \Upsilon\right)}-2\right)
$$

(3.16) becomes

$$
\frac{\mu_{z, t}^{*} \zeta_{c, t}}{c_{t} \mu_{z, t}^{*}-b c_{t-1}}-\left(1+\tau^{c}\right) \zeta_{c, t} \lambda_{z, t}=b \beta \mathrm{E}_{t}\left(\frac{\zeta_{c, t+1}}{c_{t+1} \mu_{z, t+1}^{*}-b c_{t}}\right)
$$

(3.17) becomes

$$
\zeta_{c, t} \lambda_{z, t}=\beta \mathrm{E}_{t}\left(\frac{\zeta_{c, t+1} \lambda_{z, t+1}}{\pi_{t+1} \mu_{z, t+1}^{*}} R_{t+1}\right)
$$


(3.18) becomes

$$
\begin{aligned}
& \frac{1}{\mu_{\Upsilon, t}}-q_{t}\left[1-S\left(\frac{\zeta_{I, t} \mu_{z, t}^{*} \Upsilon i_{t}}{i_{t-1}}\right)-S^{\prime}\left(\frac{\zeta_{I, t} \mu_{z, t}^{*} \Upsilon i_{t}}{i_{t-1}}\right) \frac{\zeta_{l, t} \mu_{z, t}^{*} \Upsilon}{i_{t-1}}\right] \\
& =\beta \mathrm{E}_{t}\left[\frac{\zeta_{c, t+1} \lambda_{z, t+1}}{\zeta_{c, t} \lambda_{z, t}} \frac{q_{t+1}}{\mu_{z, t+1}^{*} \Upsilon} S^{\prime}\left(\frac{\zeta_{l, t+1} \mu_{z, t+1}^{*} \Upsilon i_{t+1}}{i_{t}}\right) \zeta_{l, t+1}\left(\frac{\mu_{z, t+1}^{*} \Upsilon i_{t+1}}{i_{t}}\right)^{2}\right]
\end{aligned}
$$

(3.19) becomes

$$
\beta_{t, t+1}^{\star}=\beta \frac{1}{\mu_{z, t+1}^{*}} \frac{\zeta_{c, t+1} \lambda_{z, t+1}}{\zeta_{c, t} \lambda_{z, t}}
$$

(3.2) becomes

$$
r_{t}^{k}=\alpha \varepsilon_{t}\left(\frac{\Upsilon \mu_{z_{t}^{*}} h_{t}\left(w_{t}^{*}\right)^{\frac{\lambda w}{\lambda_{w}-1}}}{u_{t} \bar{k}_{t}}\right)^{1-\alpha} \lambda_{t}^{p}
$$

(3.3) becomes

$$
w_{t}=(1-\alpha) \varepsilon_{t}\left(\frac{\Upsilon \mu_{z_{t}^{*}} h_{t}\left(w_{t}^{*}\right)^{\frac{\lambda_{w}}{\lambda_{w}-1}}}{u_{t} \bar{k}_{t}}\right)^{-\alpha} \lambda_{t}^{p}
$$

(3.4) becomes

$$
\lambda_{t}^{p}=\frac{1}{\varepsilon_{t}}\left(\frac{r_{t}^{k}}{\alpha}\right)^{\alpha}\left(\frac{w_{t}}{1-\alpha}\right)^{1-\alpha}
$$

(3.5), (3.6), and (3.7) stay as such.

(3.13) becomes

$$
y_{z, t}=\left(p_{t}^{*}\right)^{\frac{\lambda_{f, t}}{\lambda_{f, t}-1}} \varepsilon_{t}\left[\left(\frac{u_{t} k_{t}}{\mu_{z, t} \Upsilon}\right)^{\alpha}\left(h_{t}\left(w_{t}^{*}\right)^{\frac{\lambda_{w}}{\lambda_{w}-1}}\right)^{1-\alpha}-\varphi\right]
$$

(3.23) remains as such;

(3.28) and (3.29) remain as such; (3.30) gives

$$
R_{t}^{k}=\frac{\left(1-\tau^{k}\right)\left(u_{t} r_{t}^{k}-a\left(u_{t}\right)\right)+(1-\delta) q_{t}}{\Upsilon q_{t-1}} \pi_{t}+\tau^{k} \delta
$$


As for the financial contract equations, bankers' zero profit condition (17), using (3.35), becomes

$$
\frac{q_{t} \bar{k}_{t+1}}{\bar{n}_{t+1}} \frac{R_{t+1}^{k}}{R_{t}}\left[\bar{\omega}_{t}\left(1-F_{t}\right)+G_{t}(1-\mu)\right]-\frac{q_{t} \bar{k}_{t+1}}{\bar{n}_{t+1}}+1=0
$$

(18) becomes

$$
\mathrm{E}_{t}\left\{\left[1-\Gamma_{t}\left(\bar{\omega}_{t+1}\right)\right] \frac{R_{t+1}^{k}}{R_{t}}-\lambda_{t+1}^{c}\left[1-\frac{R_{t+1}^{k}}{R_{t}}\left[\Gamma_{t}\left(\bar{\omega}_{t+1}\right)-\mu G_{t}\left(\bar{\omega}_{t+1}\right)\right]\right]\right\}=0
$$

(19) becomes

$$
\mathrm{E}_{t}\left\{R_{t}^{k} q_{t} \frac{\bar{k}_{t+1}}{m_{t+1}}\left\{\lambda_{t+1}^{c}\left[\Gamma_{t}^{\prime}\left(\bar{\omega}_{t+1}\right)-\mu G_{t}^{\prime}\left(\bar{\omega}_{t+1}\right)\right]-\Gamma_{t}^{\prime}\left(\bar{\omega}_{t+1}\right)\right\}\right\}=\mathrm{E}_{t}\left\{\frac{G_{t}^{\prime}\left(\bar{\omega}_{t+1}\right)}{\bar{\omega}_{t+1}} s^{c} \frac{d_{t+1}^{S}}{p_{t+1}^{\theta}}\right\}
$$

with $\frac{G_{t}^{\prime}\left(\bar{\omega}_{t+1}\right)}{\bar{\omega}_{t+1}}=F_{t}^{\prime}\left(\bar{\omega}_{t+1}\right)$.

As for the search equations, (2), (3), (26), and (3.37) remain as such, while (16) becomes

$$
\frac{d_{t}^{S}}{\gamma_{t} p_{t}^{\theta}}=\beta^{e} \mathrm{E}_{t}\left\{\left[1-\Gamma_{t}\left(\bar{\omega}_{t+1}\right)\right] R_{t+1}^{k} q_{t} \frac{\bar{k}_{t+1}}{m_{t+1}}+\pi_{t+1} \mu_{z, t+1}^{*}\left[\left(1-\gamma_{t+1}\right) \frac{\bar{c}_{t+1}^{e}}{m_{t+1}}+\left[1-F_{t}\left(\bar{\omega}_{t+1}\right) s^{c}\right] \frac{d_{t+1}^{S}}{p_{t+1}^{\theta}}\right]\right\}
$$

After plugging in the participation constraint (17), (22) is stationarized as

$$
\bar{n}_{t+1}=\frac{m_{t+1}}{m_{t}}\left\{\frac{\gamma_{t}}{\mu_{z, t}^{*} \pi_{t}}\left\{q_{t-1} \bar{k}_{t}\left[R_{t}^{k}-R_{t-1}-\mu G_{t-1}\left(\bar{\omega}_{t}\right) R_{t}^{k}\right]+\bar{n}_{t} R_{t-1}\right\}+\bar{w}_{t}^{e}\right\}
$$

The aggregate resource constraint (23) becomes

$$
y_{z, t}=g_{t}+c_{t}+\frac{i_{t}}{\mu_{\Upsilon, t}}+a\left(u_{t}\right) \frac{\bar{k}_{t}}{\Upsilon_{\mu_{z, t}^{*}}^{*}}+\bar{d}_{t}^{M}+\bar{c}_{t}^{e}
$$


Aggregate montoring costs (24) become

$$
\bar{d}_{t}^{M}=\mu G\left(\omega_{t}\right)\left(1+R_{t}^{k}\right) \frac{q_{t-1} \bar{k}_{t}}{\pi_{t} \mu_{z, t}^{*}},
$$

The aggregate non-survival payoff (25) becomes

$$
\bar{c}_{t}^{e}=\Theta \frac{1-\gamma_{t}}{\gamma_{t}}\left(\bar{n}_{t+1} \frac{m_{t}}{m_{t+1}}-\bar{w}_{t}^{e}\right)
$$

And monetary policy (3.38) stays as such.

The growth rate of the nominal wage (3.21) becomes

$$
\pi_{w, t} \equiv \frac{w_{t}}{w_{t-1}} \mu_{z^{*}, t} \pi_{t}
$$

